\title{
Genetics of kidney stone disease
}

2 Sarah A. Howles ${ }^{1,2}$ and Rajesh V. Thakker ${ }^{2}$

${ }^{1}$ Nuffield Department of Surgical Sciences, University of Oxford, Oxford, UK

${ }^{2}$ Academic Endocrine Unit, Radcliffe Department of Medicine, University of Oxford, Oxford, UK.

*email: rajesh.thakker@ndm.ox.ac.uk

\section{Abstract |}

Kidney stone disease (nephrolithiasis) is a common problem that can be associated with alterations in urinary solute composition including hypercalciuria. Studies suggest that the prevalence of monogenic kidney stone disorders, including renal tubular acidosis with deafness, Bartter syndrome, primary hyperoxaluria, and cystinuria, in patients attending kidney stone clinics is $\sim 15 \%$. However, for the majority of individuals, nephrolithiasis has a multifactorial aetiology involving genetic and environmental factors. Nonetheless, the genetic influence on stone formation in these idiopathic stone formers remains considerable and twin studies estimate a heritability of $>45 \%$ for nephrolithiasis and $>50 \%$ for hypercalciuria. The contribution of polygenic influences from multiple loci have been investigated by genome-wide association and candidate gene studies, which indicate that a number of genes and molecular pathways contribute to the risk of stone formation. Genetic approaches, studying both monogenic and polygenic factors in nephrolithiasis, have revealed that the following have important roles in the aetiology of kidney stones: transporters and channels; ions, protons and amino acids; the calcium-sensing receptor (a G-protein-coupled receptor) signalling pathway; and the metabolic pathways for vitamin $\mathrm{D}$, oxalate, cysteine, purines and uric acid. These advances, which have increased our understanding of the pathogenesis of nephrolithiasis, will hopefully facilitate the future development of targeted therapies for precision medicine approaches in patients with nephrolithiasis. 


\section{[H1] Introduction}

Kidney stone disease is a major clinical and economic health burden, affecting $>15 \%$ of men and $>5 \%$ of women by 70 years of age ${ }^{1}$. It results in $>80,000$ hospital episodes each year in the UK and data from the United States suggests that its prevalence has increased from 3.8\% in 19761980 to $8.8 \%$ in $2007-2010^{1-3}$. Unfortunately, kidney stones are commonly recurrent with up to $50 \%$ of individuals experiencing a second episode within 10 years of their initial presentation and treatment for recurrent stone disease has been linked to a decline in renal function ${ }^{4,5}$.

Stones that form in the kidney (FIG. 1) most commonly comprise calcium oxalate ( $65 \%)$ but can also contain calcium phosphate $(\sim 10 \%)$, uric acid $(\sim 15 \%)$, magnesium ammonium phosphate ( $\sim 10 \%)$, cystine $(\sim 1 \%), 2,8$-dihydroxyadenine $(<1 \%)$, xanthine $(<1 \%)$, or excreted drugs such as indinavir $(<1 \%)^{6-10}$. The composition of kidney stones shows worldwide geographical variation and although the proportion of calcium oxalate stones has been reported to be relatively consistent between countries, magnesium ammonium phosphate stones, which are associated with infection, are more frequent in Sub-Saharan Africa than in more developed regions ${ }^{11}$. Stones form in the urine when the relative concentrations of lithogenic substances, such as calcium or oxalate, are imbalanced with the concentrations of inhibitors of stone formation, such as citrate or magnesium, [Au: Edit OK?] resulting in crystal precipitation and aggregation ${ }^{10}$. Unsurprisingly, therefore, nephrolithiasis is often associated with metabolic abnormalities of urinary solute concentration or decreased urinary solubility; these abnormalities include hypercalciuria, hyperoxaluria, hypocitraturia, hyperuricosuria, cystinuria, low urinary volume and defects in urinary acidification ${ }^{8,12}$.

The aetiology of kidney stone disease and associated metabolic abnormalities is multifactorial, involving genetic and environmental factors. A family history of nephrolithiasis is present in 35$65 \%$ of individuals with kidney stones, whereas only $5-20 \%$ of non-stone-forming populations have a family history of this disorder ${ }^{13,14}$. Furthermore, twin studies have reported the heritability of kidney stone disease and urinary calcium excretion to be $>45 \%{ }^{15-17}$ and individuals with a 
strong family history of urolithiasis, including a parent and two siblings, have a standard incidence ratio for stone formation of $>50^{18}$. In the majority of patients, the genetic factors and pathophysiology of kidney stones are poorly understood, although in some cases, a monogenetic disorder such as primary hyperoxaluria accounts for the observed phenotype.

In the past 5 years, studies have highlighted the clinical importance of investigating patients for genetic causes of kidney stone disease and reported that $>15 \%$ of patients in specialist kidney stone clinics and $\sim 30 \%$ of recurrent stone formers under the age of 25 years have a monogenetic molecular diagnosis ${ }^{19-21}$. In addition, studies of large populations, using genome-wide association studies (GWASs) and candidate gene analysis approaches, have provided insights into the common genetic variants and molecular pathways that contribute to the risk of stone formation.

This Review briefly outlines general approaches for stone prevention, describes our current understanding of the genetic influences underlying kidney stone formation and discusses the implications of a correct diagnosis on the clinical management of recurrent stone formers.

\section{[H1] General stone prevention strategies}

Guidelines from the European Association of Urology (EAU), American Urological Association (AUA), and The National Institute for Health and Care Excellence (NICE) recommend that all patients who have had an upper urinary tract calculus should be screened for hypercalcaemic disorders with measurement of serum calcium ${ }^{22-24}$. The AUA and EAU guidelines also suggest measurement of serum uric acid to exclude hyperuricaemia ${ }^{22,23}$. Individuals with recurrent stone disease, malabsorptive intestinal disorders, medical conditions predisposing to stone formation, an early age of onset of kidney stones, and those with a family history of nephrolithiasis should be considered to be at high risk of further stone formation 22,23 . For these high risk patients, the EAU and AUA guidelines advise metabolic screening with additional blood tests and a 24-hour urine collection to assess urinary excretion of calcium, oxalate, uric acid, citrate, magnesium, 
inorganic phosphate, and cystine along with urinary $\mathrm{pH}$ and urinary volume (Box 1) ${ }^{22,23}$. In addition, analysis of stone composition can provide important information regarding the underlying diagnosis (Box 1)23.

Regardless of individual risk factors, all patients are advised to increase their daily fluid intake ${ }^{25}$, reduce animal protein consumption, and increase dietary fresh fruit and fibre ${ }^{26}$. Reduced oxalate intake is recommended in order to prevent a high urinary oxalate load ${ }^{23}$. Calcium intake should not be restricted ${ }^{27}$, although calcium supplementation is discouraged except in patients with enteric hyperoxaluria ${ }^{28}$. In addition, sodium intake should be restricted as a high sodium intake can result in increased urinary calcium excretion and a reduction in urinary citrate excretion ${ }^{29}$ (Box 1).

Other strategies aimed at preventing stone recurrence are individualized on the basis of the patient's underlying diagnosis and the results of a metabolic assessment. For those with acidic urine, with or without hypocitraturia, alkaline citrates or sodium bicarbonate will achieve alkalinization and, therefore, decrease the risk of calcium oxalate and uric acid stone formation 22. However, caution should be employed as a high urinary $\mathrm{pH}$ will encourage calcium phosphate stone formation ${ }^{22}$. Thiazide diuretics are effective in reducing urinary calcium excretion although their precise mechanism of action remains unclear ${ }^{30}$. For hyperuricosuric individuals, xanthine oxidase inhibitors such as allopurinol or febuxostat can be beneficial ${ }^{22}$.

\section{[H1] Monogenic disorders of nephrolithiasis}

The monogenetic disorders of nephrolithiasis can be classified into two categories: disorders associated with calcium-containing stones — which are radiopaque on plain abdominal X-ray — and disorders associated with stones that do not contain calcium and either demonstrate poor radiopacity or are radiolucent (Supplementary Table 1, FIG. 1).

\section{[H2] Disorders of calcium nephrolithiasis}


The disorders of calcium nephrolithiasis include autosomal dominant idiopathic hypercalciuria, autosomal dominant hypocalcaemia, Bartter syndrome, Dent disease, hereditary hypophosphataemic rickets with hypercalciuria, familial hypomagnesaemia with hypercalciuria and nephrocalcinosis, distal renal tubular acidosis, infantile hypercalcaemia, and primary hyperoxaluria (Table 1, Supplementary Table 1).

\section{[H3] Autosomal dominant idiopathic hypercalciuria}

Hypercalciuria is defined as a urinary calcium excretion of $>0.1 \mathrm{mmol} / \mathrm{kg}$ per 24 hours or $>4 \mathrm{mg} / \mathrm{kg}$ per 24 hours $^{31}$ and is the most common metabolic abnormality detected in stone formers ${ }^{10}$. Idiopathic hypercalciuria can be inherited as a monogenic disorder with an autosomal dominant pattern, or as part of a polygenic trait. Increased urinary calcium excretion can be caused by excess absorption (absorptive idiopathic hypercalciuria (AIH)) or by renal calcium leak. Patients with idiopathic hypercalciuria are normocalcaemic with normal parathyroid hormone (PTH) concentrations, but often have a low bone mineral density ${ }^{10}$. To date, two genes — adenylate cyclase $10(A D C Y 10)$ and vitamin D receptor $(V D R)$ - have been reported to be implicated in the aetiology of $\mathrm{AIH}^{32,33}$. Genetic linkage studies in three families with autosomal dominant AIH mapped the disease locus to chromosome 1q23.3-q24, which contains the ADCY10 gene that encodes a divalent cation and bicarbonate sensor (Supplementary Table 1$)^{32}$. DNA sequence analysis of $A D C Y 10$ identified six sequence variations in patients with $\mathrm{AIH}$, four of which were associated with a significantly increased relative risk of AIH 2.2-3.5-fold increased risk of $\mathrm{AIH}(\mathrm{P}<0.02)^{34}$. Additional putatively deleterious alleles have since been identified in hypercalciuric stone formers ${ }^{19,21}$.

In other genetic linkage studies of French-Canadian families with kidney stone disease and idiopathic hypercalciuria, the locus was located to $12 \mathrm{q} 12-\mathrm{q} 14$, which contains the VDR gene (Supplementary Table 1) ${ }^{33}$. Heterozygous variants in VDR have also been identified in two hypophosphataemic stone-forming patient. Hypercalciuria was not described in these two patients, however it is unclear whether this was formally assessed 21 . A locus for autosomal 
dominant hypercalciuria and nephrolithiasis has been mapped by linkage studies of a Spanish kindred to chromosome 9q33.2-q34.2 (Supplementary Table 1); this region contains approximately 170 genes, and to date, the gene causing this form of idiopathic hypercalciuria has not been identified ${ }^{35}$.

\section{[H3] Autosomal dominant hypocalcaemia}

Autosomal dominant hypocalcaemia $(\mathrm{ADH})$ is caused by heterozygous gain-of-function mutations in components of the calcium-sensing receptor (CaSR) signalling pathway, resulting in an increased sensitivity of the CaSR to alterations in extracellular calcium concentration ${ }^{36,37}$. In vitro expression analyses of ADH-associated mutants have demonstrated that the extracellular calcium concentration required to elicit a half-maximal $\left(\mathrm{EC}_{50}\right)$ increase in intracellular responses is lower than that required in cells expressing wild-type components ${ }^{36-39}$. ADH type 1 is caused by mutations in the G-protein-coupled CaSR and ADH type 2 is caused by mutations in the G-protein subunit signalling partner, Ga11 encoded by GNA11 (Supplementary Table 1) 36,37 ; in 30\% of ADH cases, the underlying molecular abnormality is unknown ${ }^{40}$. The majority of individuals with ADH have mild hypocalcaemia and are asymptomatic, but some experience carpopedal spasms and seizures.

In patients with $\mathrm{ADH}$, hypocalcaemia is coupled with serum PTH concentrations that are inappropriately low, serum phosphate concentrations that are elevated or in the uppernormal range, and serum magnesium concentrations that are either in the low or lownormal range ${ }^{36,37}$. Hypercalciuria is present in $\sim 10 \%$ of patients, putting these individuals at increased risk of developing kidney stones ${ }^{41}$. Treatment with active metabolites of vitamin D can precipitate hypercalciuria, nephrocalcinosis, nephrolithiasis, and renal impairment and should, therefore, be avoided in patients with $\mathrm{ADH}^{36}$.

\section{[H3] Bartter syndrome}


Bartter syndrome is a renal tubulopathy characterized by hypokalaemic alkalosis, hypotension, hyper-reninaemic hyperaldosteronism, increased urinary prostaglandin excretion, and hypercalciuria with nephrocalcinosis, and is caused by defective sodium chloride reabsorption in the loop of Henle ${ }^{22,43}$. To date, mutations in six genes have been described to result in this phenotype. Bartter syndrome type I is caused by mutations in the gene encoding the bumetanidesensitive sodium-potassium-chloride cotransporter (NKCC2; also known as SLC12A1); type II is caused by mutations in the gene encoding the renal outer-medullary potassium channel (ROMK; also known as $K C N J 1)$; type III is caused by mutations in the gene encoding the voltagegated chloride channel $\mathrm{ClC}-\mathrm{Kb}(C L C N K B)$; type IV is caused by mutations in the gene encoding Barttin (BSND); type V is caused by mutations of gene encoding the CaSR (CASR); and type VI has been described in one child with a mutation in the CLCN5 gene that encodes chloride channel protein 5 (ClC-5; also known as $\mathrm{H}^{+} / \mathrm{Cl}^{-}$exchange transporter 5) (FIG. 2) $)^{42-44}$. Types I-IV are autosomal recessive in inheritance, and type IV is associated with deafness owing to the expression of Barttin, a beta subunit required for the trafficking of CLC-Kb and CLC-Ka, in the potassium-secreting marginal cells of the scala media of the inner ear ${ }^{45}$. Type V Bartter syndrome displays an autosomal dominant inheritance and results from heterozygous activating mutations of the CaSR that have a much lower $\mathrm{EC}_{50}$ than those found in patients with $\mathrm{ADH}^{42,43}$; it might be that the phenotypic features of Bartter syndrome are affected by the severity of the CaSR gainof-function mutations (Supplementary Table 1). Type VI Bartter syndrome is X-linked recessive in inheritance; mutations in CLCN5 are more commonly associated with Dent disease. Treatment with non-steroidal anti-inflammatory drugs will decrease renal prostaglandin production and blockade of distal tubular sodium-potassium exchange with spironolactone will facilitate correction of the hypokalaemic metabolic alkalosis ${ }^{46}$. Electrolytes should be replaced as required ${ }^{46}$.

\section{[H3] Dent disease}

Dent disease types 1 (DD1) and 2 (DD2) are X-linked recessive disorders of proximal renal tubular function ${ }^{47,48}$. DD1 is caused by loss-of-function mutations in CLCN5 located on 
chromosome Xp11.23, and DD2 is caused by mutations in a gene located on Xq26.1 that encodes inositol polyphosphate 5-phosphatase (OCRL), which is also implicated in the oculocerebrorenal

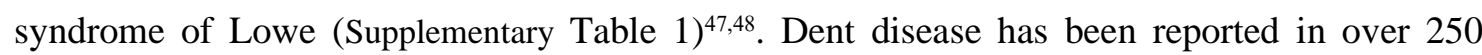
families, with men suffering from low-molecular-weight proteinuria, hypercalciuria, nephrocalcinosis, nephrolithiasis, and a progressive decline in renal function, which causes endstage renal disease in $30-80 \%$ by their fifth decade ${ }^{49}$. Female carriers of Dent disease can exhibit mild features of the disorder; hypercalciuria is reported in $50 \%$ of female carriers, but only 10 cases of female carriers suffering from nephrolithiasis have been published ${ }^{50}$. Dent disease can also be associated with other proximal tubular defects of reabsorption including aminoaciduria, phosphaturia, glycosuria, kaliuresis, uricosuria, and impaired urinary acidification; increased urinary $\mathrm{pH}$ decreases the solubility of calcium phosphate, thereby increasing the risk of nephrocalcinosis and kidney stones ${ }^{51}$. Rickets or osteomalacia are common and are the only extrarenal manifestations of the disease ${ }^{50}$.

ClC-5 is primarily expressed in the proximal tubule, thick ascending limb of the loop of Henle, and the alpha intercalated cells of the collecting duct ${ }^{52}$. ClC-5 has a role in the receptor-mediated endocytic pathway involving megalin and cubulin whereby it facilitates solute reabsorption by the proximal tubule, endosomal acidification, and trafficking of endocytic vesicles ${ }^{52}$. Dent disease-associated mutations in the $C L C N 5$ gene that encodes ClC-5 result in diminished solute reabsorption in the proximal tubule owing to impaired chloride flow and thus likely disrupted endosomal acidification and trafficking to the apical surface (FIG. 2) ${ }^{52}$.

OCRL has roles in vesicle trafficking, phagocytosis, cell adhesion and migration, cellular polarity, ciliogenesis, cytokinesis and intracellular signalling53. The OCRL variants found in DD2 are associated with a predominantly renal phenotype, although some mutations can also result in extrarenal manifestations associated with Lowe syndrome including congenital cataracts, glaucoma, mental retardation, decreased seizure threshold, muscular hypotonia, and behavioural problems ${ }^{54,55}$. OCRL mutations commonly result in a loss of 5-phosphatase activity 
of phosphatidylinositol 4, 5-bisphosphate 5-phosphatase, or decreased protein levels as a result of a reduction in expression or increased degradation owing to misfolding 56 . The exact mechanisms by which $O C R L$ mutations cause Dent disease and Lowe syndrome phenotypes is poorly understood; however, defective endocytic trafficking, defective cilia formation, and loss of cellular polarity have been implicated ${ }^{53}$. Furthermore, the severity and phenotypes of these two disorders varies widely and individuals carrying identical $O C R L$ mutations can have markedly different phenotypes, suggesting that additional genetic or environmental factors might be involved ${ }^{57}$. [Au: can you provide any examples of such factors?]

No specific therapies are available to ameliorate the hypercalciuria and renal decline observed in Dent disease. A low-sodium diet can be beneficial and thiazides can be used with careful electrolyte and fluid status monitoring 58 .

\section{[H3] Distal renal tubular acidosis}

Distal renal tubular acidosis (dRTA) is caused by defective hydrogen ion secretion by $\alpha$ intercalated cells in the distal segments of the renal tubule ${ }^{59}$. The resultant increase in urinary $\mathrm{pH}$ increases the propensity for calcium phosphate crystals to precipitate, compounded by hypercalciuria and hyperphosphaturia secondary to bone buffering, and hypocitraturia owing to increased reabsorption in response to the metabolic acidosis ${ }^{59}$. Correction of the metabolic acidosis with an alkaline citrate in patients with dRTA protects bone health via reduced requirement for skeletal buffering, increases urinary citrate excretion and reduces urinary calcium excretion, thus reducing the risk of nephrolithiasis and nephrocalcinosis ${ }^{60,61}$. dRTA can be acquired or inherited as an autosomal dominant disorder, as a result of mutation in solute carrier family 4 member 1 (SLC4A1), or as an autosomal recessive disorder, owing to mutation in ATPase $\mathrm{H}+$ transporting V1 subunit B1 (ATP6V1B1), ATPase $\mathrm{H}+$ transporting V0 subunit A4 (ATP6V0A4), carbonic anhydrase 2 (CA2), forkhead box I1 (FOXI1) or WD repeat domain 72 (WDR72) and is commonly associated with hyperchloraemia and hypokalaemia (Supplementary Table 1 and FIG. 2) $)^{59,62,63}$. 
SLC4A1 is located on chromosome $17 \mathrm{q} 21.31$ and encodes a chloride-bicarbonate exchanger, AE1 (also known as band 3 anion transport protein), which is expressed on the basolateral membrane of $\alpha$-intercalated cells (FIG. 2). AE1 also mediates chloride and bicarbonate exchange on erythrocyte membranes and polycythaemia is sometimes observed in these patients ${ }^{64}$. Homozygous or compound heterozygous mutations have also been described in Asian populations in association with dRTA, ovalocytosis and spherocytosis ${ }^{65-67}$.

ATP6V1B1 and ATP6VOA4 encode subunits B1 and A4, respectively, of the $\mathrm{H}^{+}$-ATPase (proton) pump in $\alpha$-intercalated cells (FIG. 2) ${ }^{68,69}$. Mutations in the gene encoding the B1 subunit of the proton pump in $\alpha$-intercalated cells can also be associated with sensorineural hearing loss, as the protein encoded by ATP6V1B1 has a role in ear endolymph $\mathrm{pH}$ homeostasis, and the resulting alkaline environment has been proposed to impair hair cell function ${ }^{68}$. Mouse studies have shown that the protein encoded by FOXII regulates the expression of AE1 and also expression of subunits $\mathrm{B} 1$ and $\mathrm{A} 4$ of the $\mathrm{H}^{+}$-ATPase ${ }^{63}$. Genotype-phenotype analyses of the ATP6VB1 polymorphism, rs114234874 (where the allele frequency of the major allele (G), encoding Glu161, was 94\% and allele frequency of the minor allele (A), encoding Lys161, was 6\%) in a stone-forming population revealed that those carrying the minor Lys161 variant had an increased prevalence of incomplete dRTA and an increased prevalence of calcium-phosphate stones ${ }^{70}$. Thus, the Lys161 variant of the B1 subunit of the $\alpha$-intercalated cell proton pump, which has a minor allele frequency of 3\% in the ExAC database (see Related links) might confer an increased risk of calcium-phosphate stone formation in the biochemically normal population ${ }^{71}$. Another genotype-phenotype analysis has reported that single nucleotide polymorphisms (SNPs) in ATP6VOA4 are likely to be associated with urinary $\mathrm{pH}^{72}$, and although ATP6VOA4 mutations are not typically associated with hearing loss, some patients with mutations in this gene have been reported to develop hearing loss in childhood or by the second decade of life ${ }^{73,74}$. In a cohort of 89 patients with dRTA, mutations in SLC4A1, ATP6VOA4, and ATP6VIB1 were present in $80 \%$ of the cohort, indicating that other genes are likely to be involved in the aetiology of this disease; 
however, sequencing of $C A 2, W D R 72$, and FOXI1 - mutations in which are also associated with dRTA - was not performed ${ }^{75}$

\section{[H3] Hereditary hypophosphataemic rickets with hypercalciuria}

Hereditary hypophosphataemic rickets with hypercalciuria (HHRH) is a rare autosomal recessive disorder characterized by rickets, short stature, increased renal phosphate clearance, hypercalciuria with normocalcaemia, increased gastrointestinal absorption of calcium and phosphate owing to an elevated serum concentration of 1,25-dihydroxyvitamin D, and suppressed parathyroid function ${ }^{76-80}$. HHRH was first described in a large consanguineous Bedouin kindred and homozygosity mapping studies identified that all affected individuals had a deletion in $S L C 34 A 3^{76}$, which encodes the sodium-dependent phosphate transport protein 2c (NPT2c, FIG. 2). Further studies have identified homozygous or compound heterozygous mutations in $S L C 34 A 3$ in patients with $\mathrm{HHRH}^{77-80}$. Heterozygous carriers of SLC34A3 mutations are reported to be at increased risk of renal calcification and stones, and might have increased urinary calcium excretion with or without a reduction in bone mineral density ${ }^{19,78}$ (Supplementary Table 1).

The combination of hypophosphataemia, osteoporosis and nephrolithiasis has also been reported in patients with heterozygous variants in the SLC34A1 gene encoding the sodium-dependent phosphate transport protein $2 \mathrm{a}(\mathrm{NPT} 2 \mathrm{a})^{81}$ and such mutations have been associated with hypophosphataemic hypercalciuric stone formation, without an overt skeletal phenotype, in population studies (Supplementary Table 1 and FIG. 2) ${ }^{19-21}$. In vitro expression of these identified SLC34Al variants in Xenopus laevis oocytes and opossum kidney cells to study the effects on NPT2a function yielded conflicting results, thereby questioning the role of SLC34AI in hypophosphataemic hypercalciuric stone disease ${ }^{73-75}$. However, other human and rodent in vivo studies have supported a role for SLC34Al in hypophosphataemic hypercalciuric stone disease by revealing the following: the $S L C 34 A 1$ region was significantly associated with kidney stone disease in GWASs; homozygous ablation of Slc34al (also known as Npt2a) in mice $\left(\right.$ Slc34al $\left.{ }^{--}\right)$resulted in increased urinary phosphate excretion, hypophosphataemia, elevation in 
serum levels of 1,25-dihydroxyvitamin $\mathrm{D}$, hypercalcaemia, decreased serum parathyroid hormone levels, increased serum alkaline phosphatase activity and hypercalciuria ${ }^{82}$; and that homozygous SLC34A1 mutations lead to infantile hypercalcaemia ${ }^{83-85}$. Interestingly, NPT2a is reported to interact with the sodium/hydrogen exchange regulatory cofactor NHE-RF1 (NHERF1), encoded by SLC9A3R1 and heterozygous missense $S L C 9 A 3 R 1$ variants, some of which have been shown to result in a loss-of-function in vitro, have been detected in hypophosphataemic patients with nephrolithiasis ${ }^{19-21,86}$. Moreover, mice with a targeted NHERF1 knockdown have phosphate wasting associated with an aberrant localization of Npt2a (Supplementary Table 1) ${ }^{87,88}$. Patients with $S L C 34 A 1$ and $S L C 9 A 3 R 1$ variants have a less severe bone phenotype than do those with SLC 34A3 mutations, and this might result from the ability of NPT2c to compensate, in part, for NPT2a deficiency ${ }^{89}$.

Renal phosphate wasting and hypophosphataemia can result in suppression of fibroblast growth factor 23 (FGF23), a hormone that regulates phosphate homeostasis and activates 24-hydroxylase (encoded by cytochrome P450 family 24 subfamily A member 1, CYP24A1), which is an enzyme that promotes catabolism of the active form of vitamin $\mathrm{D} 1,25-(\mathrm{OH})_{2} \mathrm{D}_{3}$ via 24-hydroxylation $\left(\right.$ FIG. 3) ${ }^{83}$. Low FGF23 levels and hypophosphataemia reduce $C Y P 24 A 1$ expression and therefore increase sensitivity to vitamin $\mathrm{D}^{83}$. Thus, vitamin $\mathrm{D}$ supplementation in these patients can result in hypercalcaemia and an increased risk of kidney stone formation and should be used with caution $^{83}$.

\section{[H3] Familial hypomagnesaemia with hypercalciuria and nephrocalcinosis}

Familial hypomagnesaemia with hypercalciuria and nephrocalcinosis (FHHNC) is a rare autosomal recessive disorder affecting the loop of Henle and the medullary thick ascending $\operatorname{limb}^{90}$. This condition is characterized by increased urinary magnesium and calcium excretion that typically presents in childhood, occasionally affected individuals will experience seizures or tetany owing to hypomagnesaemia or hypocalcaemia ${ }^{90}$. Patients might also have polydipsia and polyuria, incomplete distal renal tubular acidosis, hyperuricaemia, hypocitraturia, defects of tooth 
enamel, and $\sim 33 \%$ will have chronic renal failure by adolescence ${ }^{91-93}$. Genetic studies in 12 FHHNC kindreds identified homozygous and heterozygous missense mutations in claudin-16 (CLDN16), also referred to as paracellin-1 (PCLN-1) (Supplementary Table 1) ${ }^{90}$. To date, over 50 CLDN16 mutations have been reported in patients with $\mathrm{FHHNC}^{92}$ and in some rare cases these are related to self-limiting childhood hypercalciuria without notable disturbance of magnesium homeostasis or renal function impairment ${ }^{94}$. An identical renal phenotype with associated severe ocular involvement including macular colobomata, myopia and horizontal nystagmus has also been reported in association with CLDN19 mutations (Supplementary Table 1) (3,95. $^{\text {. }}$

Claudins are transmembrane proteins that, alongside occludin and junctional adhesion molecules, form intercellular tight junctions that mediate paracellular ion reabsorption in epithelia ${ }^{96,97}$. In the kidney, claudin-16 and claudin-19 are expressed in the thick ascending limb of the loop of Henle and confer tight junction cation selectivity, enabling reabsorption of calcium and magnesium driven by an electrochemical gradient (FIG. 2) ) $^{96,97}$. Thus, loss-of-function mutations in these proteins result in renal calcium and magnesium wasting. Claudin-16 is exclusively expressed in the kidney but claudin-19 is also expressed in human retinal pigment epithelium which accounts for the extrarenal phenotype seen with $C L D N 19$ mutations $^{98}$.

Individuals with FHHNC require magnesium supplementation to replace urinary losses, vitamin D replacement should be used with caution as this may exacerbate hypercalciuria ${ }^{92}$.

\section{[H3] Infantile hypercalcaemia}

Biallelic loss-of-function mutations in $C Y P 24 A 1$ have been reported in families with infantile hypercalcaemia and nephrocalcinosis or severe hypercalcaemia following vitamin D supplementation (Supplementary Table 1, FIG. 3) ${ }^{99}$. Furthermore, such CYP24A1 mutations have been reported in adults with hypercalcaemia and hypercalciuria, and treatment with fluconazole or ketoconazole, which are inhibitors of vitamin D synthesis, has been shown to be effective in treating hypercalcaemia and nephrolithiasis ${ }^{100-102}$. 
Biallelic mutations in SLC34Al have also been identified as being a cause of infantile hypercalcaemia associated with nephrocalcinosis and hypercalciuria; in this case, the renal phosphate wasting results in increased production of $1,25-(\mathrm{OH})_{2} \mathrm{D}_{3}$. These patients can be effectively treated with phosphate supplementation to normalize serum phosphate levels and prevent the FGF23 suppression that leads to perturbations in vitamin D and calcium metabolism ${ }^{83,103 .}$

\section{[H3] Primary hyperoxaluria}

Primary hyperoxaluria is a rare autosomal recessive disorder that is associated with excess oxalate production and urinary oxalate excretion, increasing the risk of calcium oxalate stone formation and nephrocalcinosis ${ }^{104}$. The nephrocalcinosis can lead to renal failure resulting in inadequate oxalate excretion that leads to systemic oxalate deposition in organs such as the heart, eyes, and bones ${ }^{105}$. Three forms of primary hyperoxaluria exist: primary hyperoxaluria type 1 (PH1), caused by mutations in the liver specific alanine-glyoxylate and serine-pyruvate aminotransferase $(A G X T)$, is the most severe form; $\mathrm{PH} 2$, caused by glyoxylate and hydroxypyruvate reductase $(G R H P R)$ mutations, has a slower progression to end-stage renal disease (ESRD); and $\mathrm{PH} 3$, caused by mutations in 4-hydroxy-2-oxoglutarate aldolase 1 (HOGA1), is least likely to progress to ESRD (Supplementary Table 1) ${ }^{104}$.

In PH1, the reduction in functional alanine-glyoxylate aminotransferase (AGT) results in impaired metabolism of glyoxylate to glycine leading to glyoxylate either being oxidized to oxalate or reduced to glycolate ${ }^{104,106}$. The most common AGXT mutation is pGly170Arg ( $30 \%$ of mutant alleles) and results in mis-targeting of AGT to the mitochondria, which can be ameliorated with pyridoxine treatment ${ }^{104,106}$. PH1 accounts for $\sim 80 \%$ of cases of primary hyperoxaluria and has a median age of presentation of 5.2 years, with ESRD being present in $57 \%$ of patients by 40 years of age ${ }^{104}$. In patients with PH1 who have ESRD, combined liver and renal transplantation is preferable to renal transplantation alone as it will completely correct 
the metabolic abnormality 107; a diagnosis of PH1 should therefore be considered before kidney transplantation in patients with renal failure caused by stone disease.

PH2 is caused by mutations of GRHPR, which encodes the ubiquitously expressed glyoxylate reductase/hydroxypyruvate reductase (GR/HPR) that catalyses the reduction of glyoxylate to glycolate and hydroxypyruvate to D-glycerate. In the absence of GR/HPR glyoxylate is metabolized to oxalate and hydroxypyruvate is metabolized to L-glycerate; patients with $\mathrm{PH} 2$ therefore show increased excretion of oxalate and L-glycerate ${ }^{108,109}$. PH2 accounts for $~ 10 \%$ of cases of primary hyperoxaluria, has a median age of presentation of 7.4 years and ESRD is present in $18 \%$ of patients at 40 years of age $\mathrm{e}^{104}$.

Patients with PH3 have dysfunctional 4-hydroxy-2-oxoglutarate aldolase (HOGA), an enzyme that catalyses cleavage of 4-hydroxy-2-oxoglutarate (HOG) to pyruvate and glyoxylate; the resulting accumulation of HOG is thought to inhibit GR/HPR function ${ }^{110}$. PH3 accounts for $\sim 10 \%$ of cases of $\mathrm{PH}$ and has a median age of presentation of 2.6 years; however, despite the early age of presentation, only $4 \%$ of patients have ESRD at 40 years of age ${ }^{104}$. Some HOGAI mutation carriers have been reported to be idiopathic stone formers, thereby suggesting that heterozygous $H O G A$ mutations might represent a risk factor for stone formation ${ }^{111}$.

In addition to these classical descriptions of primary hyperoxaluria, homozygous loss-of-function mutations of solute carrier family 26 member 1 (SLC26A1), which encodes the protein sulfate anion transporter 1, have been reported in two patients with nephrolithiasis, one of whom also had hyperoxaluria112. These findings are consistent with reports of hyperoxaluria and nephrolithiasis in Slc26a1 $1^{-/-}$mice ${ }^{113}$. Sulfate anion transporter 1 is a basolateral sulfate-oxalate exchanger that is expressed in the kidney, liver and intestines and the mutations reported in humans result in impaired anion exchange in HEK293T cells ${ }^{112}$.

In cases of primary hyperoxaluria restriction of oral oxalate is of limited value, inhibitors of urinary calcium oxalate crystallization might be beneficial and aggressive urinary dilution should be encouraged ${ }^{114}$. 


\section{[H2] Non-calcium nephrolithiasis disorders}

The disorders of non-calcium nephrolithiasis include cystinuria, hereditary hyperuricosuria, hereditary xanthinuria, and adenine phosphoribosyltransferase deficiency (Supplementary Table $1)$.

\section{[H3] Cystinuria}

Cystinuria arises as a result of defective amino acid transport in the proximal tubule and accounts for $\sim 5 \%$ of stone cases in the paediatric population, but only $1 \%$ of adult stone cases ${ }^{115}$. Amino acids are freely filtered at the glomerulus and, in health, $99 \%$ of filtered cysteine is reabsorbed ${ }^{115}$. Mutations in solute carrier family 3 member 1 (SLC3A1) or solute carrier family 7 member 9 (SLC7A9) which encode neutral and basic amino acid transport protein (rBAT) and $\mathrm{b}^{\mathrm{o},+}$-type amino acid transporter $1\left(\mathrm{~b}^{\mathrm{o},+} \mathrm{AT}\right)$, respectively, result in impaired reabsorption of cysteine and of the dibasic amino acids ornithine, lysine and arginine leading to hyperexcretion. rBAT and $\mathrm{b}^{\mathrm{o},+} \mathrm{AT}$ proteins form heterodimers via a disulfide bridge to make up the $\mathrm{b}^{\mathrm{o},+}$ amino acid transport system (Supplementary Table 1 and FIG. 2) ${ }^{115}$. At a normal pH, ornithine, lysine and arginine are soluble, but cysteine forms a dimer, cystine, which is relatively insoluble, resulting in crystal precipitation and stone formation ${ }^{115}$.

Historically, cystinuria was classified into three types defined by the urinary cystine excretion patterns of the heterozygous parents of affected individuals. Type I heterozygotes had a normal urinary cystine excretion $(<100 \mu \mathrm{mol} / \mathrm{g}$ creatinine $)$, type II heterozygotes demonstrated a marked increase in urinary cystine excretion ( $>900 \mu \mathrm{mol} / \mathrm{g}$ creatinine), and type III heterozygotes showed a moderate increase urinary cystine excretion $(100-900 \mu \mathrm{mol} / \mathrm{g} \text { creatinine })^{116}$. With increased understanding of the molecular basis of the disease, a new classification system with two types was adopted ${ }^{116}$. Type A is caused by defects in $S L C 3 A 1$ and is inherited in a true autosomal recessive manner, with heterozygotes having a normal urinary cystine excretion. Type B is caused by SLC7A9 variants and is autosomal dominant with incomplete penetrance, with 
heterozygotes having a variable degree of cystine hyperexcretion, some being within the normal range (Supplementary Table 1) ${ }^{117}$. A digenic inheritance has also been proposed and heterozygous type $A B$ individuals have been identified ${ }^{117}$. However, a study of patients with cystinuria has revealed that for a cystinuric phenotype, two mutated alleles in the same gene are required in addition to the mutated allele in the second gene; moreover, type $A B$ double heterozygotes were not reported to form kidney stones ${ }^{117}$.

Medical management of patients with cystinuria aims to prevent stone formation. Four main approaches are being used: urinary dilution; dietary modification to reduce intake of the cysteine precursor methionine; urinary alkalinization to increase cystine solubility; and thiol-binding drugs, such as D-penicillamine and $\alpha$-mercaptopropionylglycine, which reduce insoluble cystine to soluble cysteine ${ }^{9}$. Thiol-binding drugs are introduced if stone formation persists despite urinary alkalinization ${ }^{9}$.

\section{[H3] Hereditary hyperuricosuria}

Hereditary hyperuricosuria can result from a deficiency of the enzyme hypoxanthine-guanine phosphoribosyltransferase (HGPRT) encoded by HPRT1, hyperactivity of phosphoribosyl pyrophosphate synthase (PRPPS; also known as ribose-phosphate pyrophosphokinase 1) encoded by phosphoribosyl pyrophosphate synthetase 1 (PRPS1) or defective tubular urate reabsorption owing to mutations of solute carrier family 22 member 12 (SLC22A12) or solute carrier family 2 member 9 (SLC2A9) (Supplementary Table 1) $)^{118-120 .}$

HGPRT has a central role in purine metabolism (FIG. 4) and is encoded by HPRTl located on chromosome Xq26. HPRT1 mutations result in a partial or complete loss of enzyme function with complete deficiency being associated with Lesch-Nyhan syndrome ${ }^{118}$. Lesch-Nyhan syndrome is an $\mathrm{X}$-linked recessive disorder characterized by the following: hyperuricaemia; hyperuricosuria; uric acid urolithiasis; neurological manifestations including psychomotor delay, intellectual disability and self-mutilation; and renal failure in childhood ${ }^{118}$. Partial loss-offunction mutations in the gene that encodes hypoxanthine-guanine phosphoribosyltransferase 
(HPRT1) have a less severe phenotype and the mildest form, Kelley-Seegmiller syndrome, typically presents with uric acid stones and the metabolic manifestations of excessive purine production rather than with neurological manifestations (Supplementary Table 1)118,121.

Mutations in PRPS1, located on chromosome Xq22.3, result in increased PRPPS activity that is associated with hyperuricaemia, hyperuricosuria and gout ${ }^{122,123}$. In addition, hearing loss, uric acid stones and intellectual disability have been described in men with such mutations and some heterozygous women also have uric acid lithiasis, gout and hearing loss (Supplementary Table $1)^{119,120,124}$.

HGPRT deficiency syndrome and PRPPS superactivity can be successfully treated with xanthine oxidase inhibitors (allopurinol or febuxostat) to reduce hyperuricaemia and hyperuricosuria. However, careful titration is required in complete HGPRT deficiency and PRPPS superactivity as hyperxanthinuria and hyperhypoxanthinuria can occur ${ }^{118}$.

Loss-of-function mutations in $S L C 22 A 12$ or $S L C 2 A 9$, which encode the proximal tubular uric acid reabsorption transporters urate anion exchanger 1 (URAT1; also known as solute carrier family 22 member 12) and glucose transporter type 9 (GLUT9; also known as solute carrier family 2, facilitated glucose transporter member 9, respectively, are associated with renal uric acid wasting (FIG. 2) ${ }^{125}$. The resulting hyperuricosuria can either be asymptomatic or associated with nephrolithiasis and in a minority of patients, exercise-induced acute renal failure can occur $^{126}$. The mechanism behind this renal insult is unclear but might relate to urate nephropathy owing to increased uric acid production during exercise or owing to renal reperfusion injury as a result of exercise-induced vasoconstriction in the absence of the free-radical scavenger, uric acid $^{126}$. The disorder can occur as an autosomal recessive or an autosomal dominant disease in which patients have biallelic and heterozygous mutations, respectively ${ }^{19,125-128}$.

In all forms of hereditary hyperuricosuria urinary alkalinization will improve uric acid solubility, and should be used in combination with a high fluid intake ${ }^{129}$. Xanthine oxidase inhibitors can be beneficial in decreasing uric acid production and therefore the filtered renal load ${ }^{129,130}$. 
Hereditary xanthinuria is an autosomal recessive disorder also caused by defective purine metabolism. Two types of hereditary xanthinuria have been defined. Type 1 is the consequence of mutations in xanthine dehydrogenase $(X D H)$, and type 2 is caused by mutations in molybdenum cofactor sulfurase (MOCOS), which is an essential cofactor in the activation of XDH and aldehyde oxidase (Supplementary Table 1, FIG. 4) ${ }^{131,132}$. These enzymatic deficiencies result in reduced levels of uric acid in serum and urine and increased levels of xanthine; hypoxanthine is recycled by hypoxanthine-guanine phosphoribosyltransferase. Metabolic disturbances can be silent or can cause radiolucent xanthine urolithiasis or myopathy owing to xanthine deposits ${ }^{131,133}$. A low purine diet and high fluid intake might help to reduce the frequency of xanthine stone formation ${ }^{134}$.

Molybdenum cofactor deficiency also results in hyperxanthinuria and is caused by autosomal recessive mutations in genes encoding components of the molybdenum cofactor synthesis pathway, such as molybdenum cofactor biosynthesis protein 1 (encoded by MOCS1), molybdopterin synthase sulphur carrier subunit (encoded by MOCS2) and gephyrin (encoded by GPHN) (Supplementary Table 1) ${ }^{135}$. In addition to the biochemical phenotype of isolated xanthinuria, this disorder results in increased sulphite levels which causes psychomotor retardation, failure to thrive, seizures and hypotonia ${ }^{135,136}$.

\section{[H3] Adenine phosphoribosyltransferase deficiency}

Deficiency of adenine phosphoribosyltransferase (APRT) is caused by homozygous or compound heterozygous APRT mutations (Supplementary Table 1). Reduced APRT function causes accumulation of adenine, which is subsequently oxidized by $\mathrm{XDH}$ to form 2,8dihydroxyadenine (FIG. 4); 2,8-dihydroxyadenine is highly insoluble in urine and results in crystalluria and radiolucent 2,8-dihydroxyadenine stone disease. Nephrolithiasis is the most common clinical manifestation in patients with APRT deficiency. In addition, up to $20 \%$ of patients have end-stage renal failure at presentation owing to tubulointerstitial injury from crystal 
deposition or obstruction, which commonly leads to the requirement for renal dialysis or transplantation ${ }^{137,138}$. A diagnosis can be made by stone analysis, identification of 2,8dihydroxyadenine crystals in urine, renal biopsy, or identification of reduced APRT activity in erythrocytes ${ }^{138}$. Two types of APRT have been described based on either total (type I) or partial (type II) APRT deficiency in vitro; however, the in vitro characterization of the mutant protein does not seem to alter the in vivo phenotype ${ }^{138}$. Type II APRT has only been described in Japanese populations $^{139}$.

Allopurinol and febuxostat are effective at reducing 2,8-dihydroxyadenine production and can be used to prevent recurrent stone formation and progression of renal failure in patients with APRT $^{137,140}$. To date, $<300$ cases have been reported, but this disorder is predicted to be underdiagnosed as homozygosity at the APRT locus is estimated to be between 1 in 50,000 and 1 in $100,000^{49,138,141}$.

\section{[H1] Polygenetic nephrolithiasis risk factors}

Large-scale population-based studies have also been employed to identify genes conferring risk of kidney stone formation through candidate gene approaches and GWASs.

\section{[H2] Genome-wide association studies}

GWASs have reported associations of renal stone disease with 25 loci (Box 2)84,85,142-146. Three of these loci - CASR, CYP24A1, and SLC34A1 - are linked to genes implicated in monogenic disorders of nephrolithiasis ${ }^{19-21,36,37,83,99,103 .}$

The first GWAS in kidney stone disease was performed in Dutch and Icelandic populations in 2009 and identified two synonymous variants in claudin-14 (CLDN14, rs219779 and rs219780) that were associated with nephrolithiasis and bone mineral density ${ }^{142}$. These SNPs were also found to be associated with [Au: "increased"?] serum alkaline phosphatase (ALP), serum magnesium, serum parathyroid hormone and urinary calcium excretion ${ }^{142}$. Additional 
observational studies have confirmed correlations with SNPs in CLDN14 and urinary calcium excretion $^{147,148}$. CLDN14 encodes claudin-14, a member of the claudin transmembrane tight junction family of proteins that, like claudin-16 and claudin-19, is expressed in the thick ascending limb of the loop of Henle (FIG. 2) ${ }^{148,149}$. CaSR activation is thought to increase expression levels of claudin-14 in the thick ascending limb of the loop of Henle and thereby decrease paracellular calcium reabsorption ${ }^{149}$. In vitro studies have indicated that an intronic SNP that is associated with an increased risk of kidney stones and hypercalciuria might result in increased claudin-14 expression which might be involved in the pathophysiology of hypercalciuria ${ }^{148}$.

Results from four further kidney stone GWASs have been reported, including one trans-ethnic meta-analysis of UK and Japanese cohorts, identifying 25 loci of interest (Box 2), 11 of which have been replicated in these GWASs ${ }^{84,85,143,144}$. One replicated locus is $\sim 38 \mathrm{~kb}$ upstream of CYP24A1, mutations in which result in infantile hypercalcaemia (FIG. 3). Individuals homozygous for the increased risk allele rs 17216707 are reported to have increased mean serum calcium concentrations and more stone episodes when compared with heterozygotes ${ }^{143}$. It has been proposed that individuals carrying the $C Y P 24 A 1$ increased-risk allele might have reduced activity of the 24-hydroxylase enzyme and therefore an increased sensitivity to vitamin $\mathrm{D}^{143}$. Moreover, it has been [Au: ok to change "it has been " to "we performed a meta-analysis that"] suggested that studies are required to investigate the effects of withholding vitamin D supplementation and the use of inhibitors of vitamin D synthesis in patients who are recurrent stone formers and homozygous for the high-risk allele ${ }^{143}$.

A suggestive association between kidney stone disease and the CASR locus has been identified $\left(\mathrm{p}=2 \times 10^{-8}\right.$, significance threshold in this data set defined as $\left.\mathrm{p}<1.8 \times 10^{-9}\right)$ and subsequently replicated $\left(\mathrm{p}=3.5 \times 10^{-5}\right)^{84,143}$. Furthermore, five additional kidney stone disease locidiacylglycerol kinase delta $(D G K D)$, diacylglycerol kinase eta $(D G K H)$, WD repeat domain 72 (WDR72), GIPC1 PDZ domain containing family member 1 (GIPC1), and breakpoint cluster region $(B C R)^{143}$ - are proposed to be linked with genes that influence CaSR signalling. The 
CaSR has a central role in calcium homeostasis with gain-of-function CaSR mutations resulting in $\mathrm{ADH}$ and Bartter syndrome type V (FIG. 2) ${ }^{36,42,43}$. Furthermore, the CaSR polymorphism Arg990Gly that is found more commonly in hypercalciuric individuals than in the normocalciuric population has been reported to cause a gain-of-function in vitro ${ }^{150-152}$. However, rare variants in the CaSR were not found to be associated with urinary calcium excretion in a study of 960 individuals ${ }^{147}$, and the CaSR variants were not linked with idiopathic hypercalciuria in a nonparametric linkage analysis of 64 French Canadian sibships ${ }^{153}$. The roles of the variants in the CaSR and components of its signalling pathway in renal stone disease remain to be fully defined; however inhibitors of the CaSR (which are termed calcilytics) have been proposed as a potential therapeutic option for those carrying high-risk CaSR-associated alleles ${ }^{143}$.

ALPL encodes the alkaline phosphatase tissue-nonspecific isozyme (ALPL), which is expressed in renal proximal tubular cells, and protective alleles and risk alleles for kidney stones associated with increased and reduced ALP levels, respectively, have been defined ${ }^{84}$. These findings led to the proposal that alterations in the hydrolysis of pyrophosphate to free phosphate confers an increased risk of stone formation ${ }^{84}$. The ALPL SNP rs1256328 has since been found to be associated with kidney stone disease in a Chinese cohort ${ }^{154}$. Furthermore, loss-of-function mutations in $A L P L$ result in hereditary hypophosphatasia, which is characterized by dentition abnormalities, osteomalacia, elevated serum levels of inorganic phosphate and occasionally hypercalcaemia and/or hypercalciuria ${ }^{155}$. Other loci confirmed in other GWASs to be associated with renal stone disease include GCKR, SLC34A1, AQP1, POU2AF1, WDR72 and $U M O D^{84,85,142-146 .}$

A rare missense variant in the gene encoding transient receptor potential cation channel subfamily V member 5 (TRPV5), Leu530Arg, was found to be associated with kidney stones in an Icelandic population $^{84}$. However, this locus was not reported in subsequent studies ${ }^{143,144}$. TPRV5 is a calcium-selective cation channel that is known to be involved in intestinal and renal calcium reabsorption. TRPV5-knockout mice have been found to be hypercalciuric with enhanced intestinal calcium absorption and to have reduced cortical and trabecular bone thickness ${ }^{156}$. 
Furthermore, mice with the TRPV5 missense mutation Ser682Pro have autosomal dominant hypercalciuria ${ }^{157}$, and the missense variant Leu530Arg was found to abolish calcium uptake in Xenopus laevis oocytes in vitro ${ }^{158}$. Investigations of 20 hypercalciuric patients screened for TRPV5 polymorphisms identified eight coding sequence SNPs in TRPV5, including three nonsynonymous variants, but none of the nonsynonymous variants were shown to alter the function of TRPV5 in vitro ${ }^{159}$. However, one of these variants (rs4236480) was reported to be associated with increased stone number in a Taiwanese population ${ }^{160}$.

\section{[H2] Case-control studies}

Case-control studies have investigated the role of biologically plausible candidate genes in the development of nephrolithiasis, and have identified associations with genes including solute carrier family 26 member 6 (SLC26A6); TRPV5; transient receptor potential cation channel subfamily V member 6 (TRPVO); VDR; homeodomain-interacting protein kinase 2 (HIPK2); osteopontin ( $O P N$; also known as secreted phosphoprotein $1(S P P 1))$; matrix Gla protein $(M G P)$; and plasminogen activator, urokinase $(P L A U)^{159-162}$.

As Slc26A6-null mice have been reported to be hyperoxaluric and to develop calcium oxalate kidney stones, SLC26A6, which encodes an oxalate transporter, was investigated in a casecontrol study ${ }^{161,163}$. The case-control study identified a $S L C 26 A 6$ variant to be associated with kidney stone disease ${ }^{161}$, and this variant paradoxically was associated with increased SLC26A6 expression in the kidneys of stone-forming patients ${ }^{164}$. Case control studies have also identified that a TRPV6 haplotype might] increase the risk of absorptive hypercalciuria via increased permeability of the TRPV6 calcium channel ${ }^{162}$. Associations between common variants in VDR and kidney stone formation have been examined in multiple case-control studies with conflicting results ${ }^{165-171}$. However, two meta-analyses of these studies suggested that two [Au: is "two" correct here?] polymorphisms in the 3' untranslated region of VDR are associated with [Au: "increased"?] risk of kidney stone disease ${ }^{172,173}$. 
Case-control studies have also identified genetic polymorphisms associated with kidney stone disease in the following genes: HIPK2 (the protein product of which is thought to have a role in renal tubule epithelial cell apoptosis and renal fibrosis ${ }^{174}$; SPP1 which encodes an inhibitor of stone formation ${ }^{175-177} ; M G P$, the protein product of which inhibits hydroxyapatite nucleation and formation of calcium oxalate monohydrate ${ }^{178,179}$; and a variant in the $3^{\prime}$ UTR of the urokinase gene, which encodes a protein that degrades the organic matrix of kidney stones ${ }^{180}$. Further studies are required to elucidate the role of these genetic polymorphisms in kidney stone pathogenesis.

\section{[H1] Clinical implications}

Studies have indicated that monogenetic causes of kidney stone disease are likely underdiagnosed in the stone-forming population, particularly in individuals under 25 years of age ${ }^{19-21}$. However, these studies have also revealed that stone-forming patients with mutations in genes such as $A G X T$ or SLC34AI do not always have the classical biochemical phenotypes that are associated with these genetic variants meaning that diagnosis in practice can be difficult ${ }^{20,181}$. Failure to diagnose a monogenetic defect can result in suboptimal management and missed opportunities to screen for associated disease manifestations (FIG 5). Genetic counselling is appropriate in patients diagnosed with monogenetic disorders so that they understand the hereditary nature of their condition.

Recurrent stone formers who are children or young adults, or have a strong family history of kidney stone disease or parental consanguinity, should be considered to be at high risk of an inherited disorder ${ }^{20}$. Consideration of these patients in a multidisciplinary team that includes urologists, nephrologists, endocrinologists, clinical biochemists, and clinical geneticists should be considered to streamline relevant biochemical and genetic testing and to facilitate selection of optimal treatment strategies. For individuals with a specific biochemical phenotype, targeted screening for genetic mutations might be possible (Table 1). For others without a specific biochemical phenotype, and particularly in the paediatric population where the prevalence of 
monogenic diagnoses might be as high as $30 \%{ }^{20}$, a whole-exome sequencing approach might be required to diagnose or exclude a monogenetic diagnosis ${ }^{181}$. Establishing the genetic aetiology of the disorder in individuals with recurrent idiopathic stone formation remains a challenge, but it seems plausible that a genome-guided precision medicine approach that facilitates targeting of the relevant biological pathways might become available in the future; such approaches have not yet been attempted and would require careful evaluation in clinical trials ${ }^{143}$.

\section{[H1] Conclusions}

Kidney stone disease is a common problem with a complex aetiology that can occur as a result of a monogenetic disorder or as part of a polygenic trait. Studies of monogenic disorders of nephrolithiasis have increased our understanding of the transporters, channels, and receptors that are involved in regulation of the composition of the renal tubular fluid, and provided valuable insights into the pathways that contribute to risk of stone formation. The prevalence of monogenic stone disease has likely been underestimated and correct diagnosis will guide management, enable screening for other disease phenotypes and also facilitate genetic counselling. Furthermore, with the rapid advances that are being made in genomic medicine it is plausible that in the future, individualized drug therapies might become available based on polygenic genotype [Au: phenotype?] in individuals who are currently considered recurrent idiopathic stone formers. These precision medicine approaches might become a reality as genetic studies continue to increase our understanding of the pathways that underlie kidney stone formation.

[Au: if possible, could you adjust your referencing software so that en rules are added between the page ranges. e.g. 160-165. Thank you. If you use Endnote, the Nature Reviews style can be obtained for Endnote (see http://www.endnote.com/support/enstyles.asp).]

1. Scales, C. D., Smith, A. C., Hanley, J. M., Saigal, C. S. \& Project, U. D. in A. Prevalence of kidney stones in the United States. Eur Urol 62, 160-165 (2012).

2. Heers, H. \& Turney, B. W. Trends in urological stone disease: a 5-year update of hospital episode statistics. Bju Int 118, 785-789 (2016). 
3. Stamatelou, K. K., Francis, M. E., Jones, C. A., Nyberg, L. M. \& Curhan, G. C. Time trends in reported prevalence of kidney stones in the United States: 1976-1994. Kidney Int 63, 18171823 (2003).

4. PEARLE, M. S. et al. Medical Management of Kidney Stones: AUA Guideline. J Urology 192, 316-324 (2014).

5. Gambaro, G. et al. The Risk of Chronic Kidney Disease Associated with Urolithiasis and its Urological Treatments: A Review. J Urology 198, 268-273 (2017).

6. Goldfarb, D. S. A woman with recurrent calcium phosphate kidney stones. Clin J Am Soc Nephro 7, 1172-1178 (2012).

7. Ma, Q. et al. Uric acid stones, clinical manifestations and therapeutic considerations. Postgrad Med J 94, 458-462 (2018).

8. Coe, F. L. Kidney stone disease. J Clin Invest 115, 2598-2608 (2005).

9. Thomas, K., Wong, K., Withington, J., Bultitude, M. \& Doherty, A. Cystinuria-a urologist's perspective. Nat Rev Urol 11, 270-277 (2014).

10. Coe, F. L., Worcester, E. M. \& Evan, A. P. Idiopathic hypercalciuria and formation of calcium renal stones. Nat Rev Nephrol 12, 519-533 (2016).

11. Daudon, M. et al. [Composition of renal stones currently observed in non-industrialized countries]. Progrès En Urologie J De L'association Française D'urologie Et De La Société Française D'urologie 14, 1151-61 (2004).

12. Frick, K. K. Molecular Mechanisms of Primary Hypercalciuria. J Am Soc Nephrol 14, 1082-1095 (2003).

13. Resnick, M., Pridgen, D. B. \& Goodman, H. O. Genetic predisposition to formation of calcium oxalate renal calculi. New Engl J Medicine 278, 1313-1318 (1968).

14. Curhan, G. C., Willett, W. C., Rimm, E. B. \& Stampfer, M. J. Family history and risk of kidney stones. Journal of the American Society of Nephrology 8, 1568-1573 (1997).

15. Goldfarb, D. S., Avery, A. R., Beara-Lasic, L., Duncan, G. E. \& Goldberg, J. A Twin Study of Genetic Influences on Nephrolithiasis in Women and Men. Kidney Int Reports 4, 535-540 (2019).

16. Goldfarb, D. S., Fischer, M. E., Keich, Y. \& Goldberg, J. A twin study of genetic and dietary influences on nephrolithiasis: A report from the Vietnam Era Twin (VET) Registry. Kidney Int 67, 1053-1061 (2005).

17. Hunter, D. J. et al. Genetic contribution to renal function and electrolyte balance: a twin study. Clin Sci 103, 259-265 (2002).

18. Hemminki, K. et al. Familial risks in urolithiasis in the population of Sweden. Bju Int 121, 479-485 (2018).

19. Halbritter, J. et al. Fourteen Monogenic Genes Account for $15 \%$ of Nephrolithiasis/Nephrocalcinosis. J Am Soc Nephrol 26, 543-551 (2015). 
20. Daga, A. et al. Whole exome sequencing frequently detects a monogenic cause in early onset nephrolithiasis and\&nbsp;nephrocalcinosis. Kidney Int 93, 204-213 (2018).

21. Braun, D. A. et al. Prevalence of Monogenic Causes in Pediatric Patients with Nephrolithiasis or Nephrocalcinosis. Clin J Am Soc Nephro 11, 664-672 (2016).

22. Türk, C. et al. Guidelines on Urolithiasis. Retrieved from https://uroweb.org/guideline/urolithiasis. Access date 20/04/20.

23. Pearle, M. S. et al. Medical Management of Kidney Stones (2019). Retrieved from https://www.auanet.org/guidelines/kidney-stones-medical-mangement-guideline. Access date 20/04/20.

24. NICE Guideline - Renal and ureteric stones: assessment and management. Bju Int 123, 220-232 (2019).

25. Borghi, L. et al. Urinary Volume, Water and Recurrences in Idiopathic Calcium Nephrolithiasis: A 5-year Randomized Prospective Study. J Urology 155, 839-843 (1996).

26. Turney, B. W. et al. Diet and risk of kidney stones in the Oxford cohort of the European Prospective Investigation into Cancer and Nutrition (EPIC). Eur J Epidemiol 29, 363-369 (2014).

27. Siener, R., Ebert, D., Nicolay, C. \& Hesse, A. Dietary risk factors for hyperoxaluria in calcium oxalate stone formers. Kidney Int 63, 1037-1043 (2003).

28. Fink, H. A. et al. Diet, Fluid, or Supplements for Secondary Prevention of Nephrolithiasis: A Systematic Review and Meta-Analysis of Randomized Trials. Eur Urol 56, $72-80$ (2009).

29. Ticinesi, A., Nouvenne, A., Maalouf, N. M., Borghi, L. \& Meschi, T. Salt and nephrolithiasis. Nephrol Dial Transpl 31, 39-45 (2016).

30. Bergsland, K. J., Worcester, E. M. \& Coe, F. L. Role of proximal tubule in the hypocalciuric response to thiazide of patients with idiopathic hypercalciuria. Am J Physiolrenal 305, F592-F599 (2013).

31. Curhan, G. C., Willett, W. C., Speizer, F. E. \& Stampfer, M. J. Twenty-four-hour urine chemistries and the risk of kidney stones among women and men. Kidney Int 59, 2290-2298 (2001).

32. Reed, B. Y., Heller, H. J., Gitomer, W. L. \& Pak, C. Y. Mapping a gene defect in absorptive hypercalciuria to chromosome 1q23.3-q24. J Clin Endocrinol Metabolism 84, 3907-3913 (1999).

33. Scott, P. et al. Suggestive evidence for a susceptibility gene near the vitamin D receptor locus in idiopathic calcium stone formation. Journal of the American Society of Nephrology 10 , 1007-1013 (1999).

34. Reed, B. Y. et al. Identification and characterization of a gene with base substitutions associated with the absorptive hypercalciuria phenotype and low spinal bone density. J Clin Endocrinol Metabolism 87, 1476-1485 (2002). 
35. Wolf, M. T. F. et al. Mapping a new suggestive gene locus for autosomal dominant nephrolithiasis to chromosome 9q33.2-q34.2 by total genome search for linkage. Nephrol Dial Transpl 20, 909-914 (2005).

36. Pearce, S. H. et al. A familial syndrome of hypocalcemia with hypercalciuria due to mutations in the calcium-sensing receptor. New Engl J Medicine 335, 1115-1122 (1996).

37. Nesbit, M. A. et al. Mutations affecting G-protein subunit $\alpha 11$ in hypercalcemia and hypocalcemia. New Engl J Medicine 368, 2476-2486 (2013).

38. Gorvin, C. M. et al. Calcium-sensing receptor residues with loss- and gain-of-function mutations are located in regions of conformational change and cause signalling bias. Hum Mol Genet 27, 3720-3733 (2018).

39. Gorvin, C. M. et al. G $\alpha 11$ mutation in mice causes hypocalcemia rectifiable by calcilytic therapy. Jci Insight 2, e91103 (2017).

40. Hannan, F. M., Babinsky, V. N. \& Thakker, R. V. Disorders of the calcium-sensing receptor and partner proteins: insights into the molecular basis of calcium homeostasis. $J \mathrm{Mol}$ Endocrinol 57, R127-42 (2016).

41. Yamamoto, M., Akatsu, T., Nagase, T. \& Ogata, E. Comparison of hypocalcemic hypercalciuria between patients with idiopathic hypoparathyroidism and those with gain-offunction mutations in the calcium-sensing receptor: is it possible to differentiate the two disorders? J Clin Endocrinol Metabolism 85, 4583-4591 (2000).

42. Vargas-Poussou, R. Functional Characterization of a Calcium-Sensing Receptor Mutation in Severe Autosomal Dominant Hypocalcemia with a Bartter-Like Syndrome. J Am Soc Nephrol 13, 2259-2266 (2002).

43. Watanabe, S. et al. Association between activating mutations of calcium-sensing receptor and Bartter's syndrome. Lancet 360, 692-694 (2002).

44. Bogdanović, R. et al. A novel CLCN5 mutation in a boy with Bartter-like syndrome and partial growth hormone deficiency. Pediatr Nephrol 25, 2363-2368 (2010).

45. Janssen, A. G. H. et al. Disease-Causing Dysfunctions of Barttin in Bartter Syndrome Type IV. J Am Soc Nephrol 20, 145-153 (2009).

46. Seyberth, H. W. \& Schlingmann, K. P. Bartter- and Gitelman-like syndromes: salt-losing tubulopathies with loop or DCT defects. Pediatr Nephrol 26, 1789-1802 (2011).

47. Lloyd, S. E. et al. A common molecular basis for three inherited kidney stone diseases. Nature 379, 445-449 (1996).

48. Jr., R. R. H. et al. Dent Disease with Mutations in OCRL1. Am J Hum Genetics 76, 260-267 (2005).

49. Edvardsson, V. O. et al. Hereditary causes of kidney stones and chronic kidney disease. Pediatr Nephrol 28, 1923-1942 (2013).

50. Devuyst, O. \& Thakker, R. V. Dent's disease. Orphanet J Rare Dis 5, 28 (2010). 
51. Wrong, O. M., Norden, A. G. \& Feest, T. G. Dent's disease; a familial proximal renal tubular syndrome with low-molecular-weight proteinuria, hypercalciuria, nephrocalcinosis, metabolic bone disease, progressive renal failure and a marked male predominance. QJM: monthly journal of the Association of Physicians 87, 473-493 (1994).

52. Gorvin, C. M. et al. Receptor-mediated endocytosis and endosomal acidification is impaired in proximal tubule epithelial cells of Dent disease patients. Proc National Acad Sci 110, 7014-7019 (2013).

53. Mehta, Z. B., Pietka, G. \& Lowe, M. The Cellular and Physiological Functions of the Lowe Syndrome Protein OCRL1. Traffic 15, 471-487 (2014).

54. Lowe, C. U., Terrey, M. \& MacLachlan, E. A. Organic-aciduria, decreased renal ammonia production, hydrophthalmos, and mental retardation; a clinical entity. A.M.A. American journal of diseases of children 83, 164-184 (1952).

55. Bockenhauer, D. et al. Renal Phenotype in Lowe Syndrome: A Selective Proximal Tubular Dysfunction. Clin J Am Soc Nephro 3, 1430-1436 (2008).

56. Hichri, H. et al. From Lowe syndrome to Dent disease: correlations between mutations of the OCRL1 gene and clinical and biochemical phenotypes. Hum Mutat 32, 379-388 (2011).

57. Leahey, A. M., Charnas, L. R. \& Nussbaum, R. L. Nonsense mutations in the OCRL-1 gene in patients with the oculocerebrorenal syndrome of Lowe. Human Molecular Genetics 2, 461463 (1993).

58. Blanchard, A. et al. Effect of Hydrochlorothiazide on Urinary Calcium Excretion in Dent Disease: An Uncontrolled Trial. Am J Kidney Dis 52, 1084-1095 (2008).

59. Alonso-Varela, M. et al. Distal renal tubular acidosis. Clinical manifestations in patients with different underlying gene mutations. Pediatr Nephrol 33, 1-7 (2018).

60. Fuster, D. G. \& Moe, O. W. Incomplete Distal Renal Tubular Acidosis and Kidney Stones. Adv Chronic Kidney D 25, 366-374 (2018).

61. Domrongkitchaiporn, S. et al. Bone histology and bone mineral density after correction of acidosis in distal renal tubular acidosis. Kidney Int 62, 2160-2166 (2002).

62. Rungroj, N. et al. Distal renal tubular acidosis caused by tryptophan-aspartate repeat domain 72( WDR72) mutations. Clin Genet 94, 409-418 (2018).

63. Enerbäck, S. et al. Acidosis and Deafness in Patients with Recessive Mutations in FOXI1. $J$ Am Soc Nephrol 29, 1041-1048 (2018).

64. Agroyannis, B., Koutsikos, D., Tzanatos-Exarchou, H. \& Yatzidis, H. Erythrocytosis in type I renal tubular acidosis with nephrocalcinosis. Nephrol Dial Transpl 7, 365-366 (1992).

65. Wrong, O., Bruce, L. J., Unwin, R. J., Toye, A. M. \& Tanner, M. J. A. Band 3 mutations, distal renal tubular acidosis, and Southeast Asian ovalocytosis. Kidney Int 62, 10-19 (2002).

66. Vasuvattakul, S. et al. Autosomal recessive distal renal tubular acidosis associated with Southeast Asian ovalocytosis. Kidney Int 56, 1674-1682 (1999). 
67. Tanphaichitr, V. S. et al. Novel AE1 mutations in recessive distal renal tubular acidosis. Loss-of-function is rescued by glycophorin A. J Clin Invest 102, 2173-2179 (1998).

68. Karet, F. E. et al. Mutations in the gene encoding B1 subunit of H+-ATPase cause renal tubular acidosis with sensorineural deafness. Nat Genet 21, 84-90 (1999).

69. Karet, F. E. et al. Localization of a Gene for Autosomal Recessive Distal Renal Tubular Acidosis with Normal Hearing (rdRTA2) to 7q33-34. Am J Hum Genetics 65, 1656-1665 (1999).

70. Dhayat, N. A. et al. The Vacuolar H +-ATPase B1 Subunit Polymorphism p.E161K Associates with Impaired Urinary Acidification in Recurrent Stone Formers. J Am Soc Nephrol 27, 1544-1554 (2016).

71. Sayer, J. A. Progress in Understanding the Genetics of Calcium-Containing Nephrolithiasis. J Am Soc Nephrol 28, 748-759 (2017).

72. Canales, B. K. et al. Polymorphisms in Renal Ammonia Metabolism Genes Correlate With 24-Hour Urine pH. Kidney Int Reports 2, 1111-1121 (2017).

73. Vargas-Poussou, R. et al. Genetic Investigation of Autosomal Recessive Distal Renal Tubular Acidosis: Evidence for Early Sensorineural Hearing Loss Associated with Mutations in the ATP6V0A4Gene. J Am Soc Nephrol 17, 1437-1443 (2006).

74. Besouw, M. T. P. et al. Clinical and molecular aspects of distal renal tubular acidosis in children. Pediatr Nephrol 32, 1-10 (2017).

75. Palazzo, V. et al. The genetic and clinical spectrum of a large cohort of patients with distal renal tubular acidosis. Kidney Int 91, 1243-1255 (2017).

76. Tieder, M. et al. Hereditary hypophosphatemic rickets with hypercalciuria. New Engl J Medicine 312, 611-617 (1985).

77. Chi, Y. et al. A compound heterozygous mutation in SLC34A3 causes hereditary hypophosphatemic rickets with hypercalciuria in a Chinese patient. Bone 59, 114-121 (2014).

78. Dasgupta, D. et al. Mutations in SLC34A3/NPT2cAre Associated with Kidney Stones and Nephrocalcinosis. J Am Soc Nephrol 25, 2366-2375 (2014).

79. Acar, S. et al. Clinical and genetic characteristics of 15 families with hereditary hypophosphatemia: Novel Mutations in PHEX and SLC34A3. Plos One 13, e0193388 17 (2018).

80. Braithwaite, V., Pettifor, J. M. \& Prentice, A. Novel SLC34A3 mutation causing hereditary hypophosphataemic rickets with hypercalciuria in a Gambian family. Bone 53, 216-220 (2013).

81. Prié, D. et al. Nephrolithiasis and osteoporosis associated with hypophosphatemia caused by mutations in the type 2a sodium-phosphate cotransporter. New Engl J Medicine 347, 983991 (2002).

82. Beck, L. et al. Targeted inactivation of Npt 2 in mice leads to severe renal phosphate wasting, hypercalciuria, and skeletal abnormalities. Proc National Acad Sci 95, 5372-5377 (1998). 
83. Schlingmann, K. P. et al. Autosomal-Recessive Mutations in SLC34A1 Encoding SodiumPhosphate Cotransporter 2A Cause Idiopathic Infantile Hypercalcemia. J Am Soc Nephrol 27, 604-614 (2016).

84. Oddsson, A. et al. Common and rare variants associated with kidney stones and biochemical traits. Nat Commun 6, 7975 (2015).

85. Urabe, Y. et al. A Genome-Wide Association Study of Nephrolithiasis in the Japanese Population Identifies Novel Susceptible Loci at 5q35.3, 7p14.3, and 13q14.1. Plos Genet 8, e1002541 7 (2012).

86. Karim, Z. et al. NHERF1 mutations and responsiveness of renal parathyroid hormone. New Engl J Medicine 359, 1128-1135 (2008).

87. Gisler, S. M. et al. Interaction of the Type IIa Na/P iCotransporter with PDZ Proteins. $J$ Biol Chem 276, 9206-9213 (2001).

88. Shenolikar, S., Voltz, J. W., Minkoff, C. M., Wade, J. B. \& Weinman, E. J. Targeted disruption of the mouse NHERF-1 gene promotes internalization of proximal tubule sodiumphosphate cotransporter type IIa and renal phosphate wasting. Proc National Acad Sci 99, 11470-11475 (2002).

89. Bergwitz, C. et al. SLC34A3 mutations in patients with hereditary hypophosphatemic rickets with hypercalciuria predict a key role for the sodium-phosphate cotransporter NaPi-IIc in maintaining phosphate homeostasis. Am J Hum Genet 78, 179-92 (2005).

90. Simon, D. B. et al. Paracellin-1, a renal tight junction protein required for paracellular Mg2+ resorption. Science 285, 103-106 (1999).

91. Weber, S. et al. Novel paracellin-1 mutations in 25 families with familial hypomagnesemia with hypercalciuria and nephrocalcinosis. Journal of the American Society of Nephrology 12, 1872-1881 (2001).

92. Claverie-Martin, F. Familial hypomagnesaemia with hypercalciuria and nephrocalcinosis: clinical and molecular characteristics. Clin Kidney J 8, 656-664 (2015).

93. Yamaguti, P. M. et al. Amelogenesis imperfecta in familial hypomagnesaemia and hypercalciuria with nephrocalcinosis caused by CLDN19 gene mutations. J Med Genet 54, 2637 (2017).

94. Müller, D. et al. A Novel Claudin 16 Mutation Associated with Childhood Hypercalciuria Abolishes Binding to ZO-1 and Results in Lysosomal Mistargeting. Am J Hum Genetics 73, 1293-1301 (2003).

95. Konrad, M. et al. Mutations in the Tight-Junction Gene Claudin 19 (CLDN19) Are Associated with Renal Magnesium Wasting, Renal Failure, and Severe Ocular Involvement. Am J Hum Genetics 79, 949-957 (2006).

96. Hou, J. et al. Claudin-16 and claudin-19 interaction is required for their assembly into tight junctions and for renal reabsorption of magnesium. Proc National Acad Sci 106, 15350-15355 (2009). 
97. Hou, J. et al. Claudin-16 and claudin-19 interact and form a cation-selective tight junction complex. J Clin Invest 118, 1-11 (2008).

98. Peng, S., Gan, G., Rao, V. S., Adelman, R. A. \& Rizzolo, L. J. Effects of Proinflammatory Cytokines on the Claudin-19 Rich Tight Junctions of Human Retinal Pigment Epithelium. Invest Ophth Vis Sci 53, 5016-28 (2012).

99. Schlingmann, K. P. et al. Mutations in CYP24A1 and idiopathic infantile hypercalcemia. New Engl J Medicine 365, 410-421 (2011).

100. Molin, A. et al. CYP24A1Mutations in a Cohort of Hypercalcemic Patients: Evidence for a Recessive Trait. J Clin Endocrinol Metabolism 100, E1343-E1352 (2015).

101. Sayers, J. et al. Successful treatment of hypercalcaemia associated with a CYP24A1 mutation with fluconazole. Clin Kidney J 8, 453-455 (2015).

102. Peiris, E. D. \& Wusirika, R. A Case Report of Compound Heterozygous CYP24A1 Mutations Leading to Nephrolithiasis Successfully Treated with Ketoconazole. Case Reports Nephrol Dialysis 7, 167-171 (2018).

103. Hureaux, M. et al. Prenatal hyperechogenic kidneys in three cases of infantile hypercalcemia associated with SLC34A1 mutations. Pediatr Nephrol 33, 1-7 (2018).

104. Hopp, K. et al. Phenotype-Genotype Correlations and Estimated Carrier Frequencies of Primary Hyperoxaluria. J Am Soc Nephrol 26, 2559-2570 (2015).

105. Lorenz, E. C., Michet, C. J., Milliner, D. S. \& Lieske, J. C. Update on Oxalate Crystal Disease. Curr Rheumatol Rep 15, 1264-9 (2013).

106. Pey, A. L., Salido, E. \& Sanchez-Ruiz, J. M. Role of low native state kinetic stability and interaction of partially unfolded states with molecular chaperones in the mitochondrial protein mistargeting associated with primary hyperoxaluria. Amino Acids 41, 1233-1245 (2010).

107. Dhondup, T., Lorenz, E. C., Milliner, D. S. \& Lieske, J. C. Combined Liver-Kidney Transplantation for Primary Hyperoxaluria Type 2: A Case Report. Am J Transplant 18, 253257 (2018).

108. Cramer, S. D., Ferree, P. M., Lin, K., Milliner, D. S. \& Holmes, R. P. The Gene Encoding Hydroxypyruvate Reductase (GRHPR) is Mutated in Patients with Primary Hyperoxaluria Type II. Hum Mol Genet 8, 2063-2069 (1999).

109. MBChB, C.-W. L. et al. Novel mutation in the GRHPR gene in a Chinese patient with primary hyperoxaluria type 2 requiring renal transplantation from a living related donor. $A m J$ Kidney Dis 38, 1307-1310 (2001).

110. Riedel, T. J. et al. Structural and Biochemical Studies of Human 4-hydroxy-2-oxoglutarate Aldolase: Implications for Hydroxyproline Metabolism in Primary Hyperoxaluria. Plos One 6, e26021-15 (2011).

111. Monico, C. G. et al. Primary Hyperoxaluria Type III Gene HOGA1 (Formerly DHDPSL) as a Possible Risk Factor for Idiopathic Calcium Oxalate Urolithiasis. Clin J Am Soc Nephro 6, 2289-2295 (2011). 
112. Gee, H. Y. et al. REPOR T Mutations in SLC26A1 Cause Nephrolithiasis. Am J Hum Genetics 98, 1228-1234 (2016).

113. Dawson, P. A. et al. Urolithiasis and hepatotoxicity are linked to the anion transporter Sat 1 in mice. J Clin Invest 120, 706-712 (2010).

114. Cochat, P. et al. Primary hyperoxaluria Type 1: indications for screening and guidance for diagnosis and treatment. Nephrol Dial Transpl 27, 1729-1736 (2012).

115. Biyani, C. S. \& Cartledge, J. J. Cystinuria—Diagnosis and Management. Eau-ebu Updat Ser 4, 175-183 (2006).

116. Strologo, L. D. Comparison between SLC3A1 and SLC7A9 Cystinuria Patients and Carriers: A Need for a New Classification. J Am Soc Nephrol 13, 2547-2553 (2002).

117. Font-Llitjos, M. New insights into cystinuria: 40 new mutations, genotype-phenotype correlation, and digenic inheritance causing partial phenotype. J Med Genet 42, 58-68 (2005).

118. Torres, R. J. \& Puig, J. G. Hypoxanthine-guanine phosophoribosyltransferase (HPRT) deficiency: Lesch-Nyhan syndrome. Orphanet J Rare Dis 2, 48 (2007) https://doi.org/10.1186/1750-1172-2-48.

119. Nyhan, W. L., James, J. A., Teberg, A. J., Sweetman, L. \& Nelson, L. G. A new disorder of purine metabolism with behavioral manifestations. J Pediatrics 74, 20-27 (1969).

120. Simmonds, H. A., Webster, D. R., Wilson, J. \& Lingham, S. An X-linked syndrome characterised by hyperuricaemia, deafness, and neurodevelopmental abnormalities. Lancet 320, 68-70 (1982).

121. Zoref-Shani, E., Feinstein, S., Frishberg, Y., Bromberg, Y. \& Sperling, O. KelleySeegmiller syndrome due to a unique variant of hypoxanthine-guanine phosphoribosyltransferase: reduced affinity for 5-phosphoribosyl-1-pyrophosphate manifested only at low, physiological substrate concentrations. Biochimica Et Biophysica Acta Bba-Mol Basis Dis 1500, 197-203 (2000).

122. Zoref, E., Vries, A. D. \& Sperling, O. Mutant feedback-resistant phosphoribosylpyrophosphate synthetase associated with purine overproduction and gout. Phosphoribosylpyrophosphate and purine metabolism in cultured fibroblasts. J Clin Invest 56, 1093-1099 (1975).

123. Roessler, B. J. et al. Human X-linked phosphoribosylpyrophosphate synthetase superactivity is associated with distinct point mutations in the PRPS1 gene. Journal of Biological Chemistry 268, 26476-26481 (1993).

124. Becker, M. A., Raivio, K. O., Bakay, B., Adams, W. B. \& Nyhan, W. L. Variant human phosphoribosylpyrophosphate synthetase altered in regulatory and catalytic functions. J Clin Invest 65, 109-120 (1980).

125. Matsuo, H. et al. Mutations in Glucose Transporter 9 Gene SLC2A9 Cause Renal Hypouricemia. Am J Hum Genetics 83, 744-751 (2008).

126. Ichida, K. Clinical and Molecular Analysis of Patients with Renal Hypouricemia in JapanInfluence of URAT1 Gene on Urinary Urate Excretion. J Am Soc Nephrol 15, 164-173 (2004). 
127. Tasic, V. et al. Clinical and Functional Characterization of URAT1 Variants. Plos One 6, e28641 8 (2011).

128. Dinour, D. et al. Homozygous SLC2A9Mutations Cause Severe Renal Hypouricemia. $J$ Am Soc Nephrol 21, 64-72 (2010).

129. Ng, N., Kaur, A. \& Shenoy, M. Recurrent kidney stones in a child with Lesch-Nyhan syndrome: Answers. Pediatr Nephrol 34, 425-427 (2019).

130. Bhasin, B. et al. Hereditary Renal Hypouricemia: A New Role for Allopurinol? Am J Medicine 127, e3-e4 (2014).

131. Ichida, K. et al. Identification of two mutations in human xanthine dehydrogenase gene responsible for classical type I xanthinuria. J Clin Invest 99, 2391-2397 (1997).

132. Ichida, K., Matsumura, T., Sakuma, R., Hosoya, T. \& Nishino, T. Mutation of Human Molybdenum Cofactor Sulfurase Gene Is Responsible for Classical Xanthinuria Type II. Biochem Bioph Res Co 282, 1194-1200 (2001).

133. NAGAE, A. et al. Asymptomatic Hereditary Xanthinuria: A Case Report. Jpn J Med 29, 287-291 (1990).

134. Fildes, R. D. Hereditary xanthinuria with severe urolithiasis occurring in infancy as renal tubular acidosis and hypercalciuria. J Pediatrics 115, 277-280 (1989).

135. Reiss, J. \& Hahnewald, R. Molybdenum cofactor deficiency: Mutations in GPHN, MOCS1, and MOCS2. Hum Mutat 32, 10-18 (2010).

136. Zaki, M. S. et al. Molybdenum cofactor and isolated sulphite oxidase deficiencies: Clinical and molecular spectrum among Egyptian patients. Eur J Paediatr Neuro 20, 714-722 (2016).

137. Runolfsdottir, H. L., Palsson, R, Agustsdottir, I.M., Indridason, O. S., \& Edvardsson, V. O. Kidney Disease in Adenine Phosphoribosyltransferase Deficiency. Am J Kidney Dis 67, 431- 438 (2016).

138. Bollée, G. et al. Phenotype and Genotype Characterization of Adenine Phosphoribosyltransferase Deficiency. J Am Soc Nephrol 21, 679-688 (2010).

139. Kamatani, N., Terai, C., Kuroshima, S., Nishioka, K. \& Mikanagi, K. Genetic and clinical studies on 19 families with adenine phosphoribosyltransferase deficiencies. Human Genetics 75, 163-168 (1987).

140. Edvardsson, V. O. et al. Comparison of the effect of allopurinol and febuxostat on urinary 2,8-dihydroxyadenine excretion in patients with Adenine phosphoribosyltransferase deficiency (APRTd)_ A clinical trial. Eur J Intern Med 48, 75-79 (2018).

141. Jaffer, A., Joyce, A., Koenig, P. \& Biyani, C. S. Adenine Phosphoribosyltransferase Deficiency: A Rare Cause of Recurrent Urolithiasis. J Endourology Case Reports 3, 49-51 (2017).

142. Thorleifsson, G. et al. Sequence variants in the CLDN14 gene associate with kidney stones and bone mineral density. Nat Genet 41, 926-930 (2009). 
143. Howles, S. A. et al. Genetic variants of calcium and vitamin D metabolism in kidney stone disease. Nat Commun 10, 5175 (2019).

144. Tanikawa, C. et al. Novel Risk Loci Identified in a Genome-Wide Association Study of Urolithiasis in a Japanese Population. J Am Soc Nephrol 30, 855-864 (2019).

145. Gudbjartsson, D. F. et al. Association of Variants at UMOD with Chronic Kidney Disease and Kidney Stones-Role of Age and Comorbid Diseases. Plos Genet 6, e1001039 (2010).

146. Benonisdottir, S. et al. Sequence variants associating with urinary biomarkers. Hum Mol Genet 28, 1199-1211 (2019).

147. Toka, H. R., Genovese, G., Mount, D. B., Pollak, M. R. \& Curhan, G. C. Frequency of Rare Allelic Variation in Candidate Genes among Individuals with Low and High Urinary Calcium Excretion. Plos One 8, e71885-8 (2013).

148. Ure, M. E. et al. A variant in a cis-regulatory element enhances claudin-14 expression and is associated with pediatric-onset hypercalciuria and kidney stones. Hum Mutat 38, 649-657 (2017).

149. Dimke, H. et al. Activation of the $\mathrm{Ca} 2+$-sensing receptor increases renal claudin-14 expression and urinary Ca 2+excretion. Am J Physiol-renal 304, F761-F769 (2013).

150. Vezzoli, G. et al. R990G polymorphism of calcium-sensing receptor does produce a gainof-function and predispose to primary hypercalciuria. Kidney Int 71, 1155-1162 (2007).

151. Vezzoli, G. Influence of Calcium-Sensing Receptor Gene on Urinary Calcium Excretion in Stone-Forming Patients. J Am Soc Nephrol 13, 2517-2523 (2002).

152. Liu, K. et al. The G allele of CaSR R990G polymorphism increases susceptibility to urolithiasis and hypercalciuria: evidences from a comprehensive meta-analysis. Biomed Res Int 2015, 958207-12 (2015).

153. Petrucci, M. et al. Evaluation of the calcium-sensing receptor gene in idiopathic hypercalciuria and calcium nephrolithiasis. Kidney Int 58, 38-42 (2000).

154. Li, X. et al. Common Variants in ALPLGene Contribute to the Risk of Kidney Stones in the Han Chinese Population. Genet Test Mol Bioma 22, 187-192 (2018).

155. Whyte, M. P. Hypophosphatasia - aetiology, nosology, pathogenesis, diagnosis and treatment. Nat Rev Endocrinol 12, 233-246 (2016).

156. Hoenderop, J. G. J. et al. Renal Ca2+ wasting, hyperabsorption, and reduced bone thickness in mice lacking TRPV5. J Clin Invest 112, 1906-1914 (2003).

157. Loh, N. Y. et al. Autosomal dominant hypercalciuria in a mouse model due to a mutation of the epithelial calcium channel, TRPV5. Plos One 8, e55412 (2013).

158. Wang, L., Holmes, R. P. \& Peng, J.-B. The L530R variation associated with recurrent kidney stones impairs the structure and function of TRPV5. Biochem Bioph Res Co 492, 362367 (2017). 
159. Renkema, K. Y. et al. TRPV5 gene polymorphisms in renal hypercalciuria. Nephrol Dial Transpl 24, 1919-1924 (2009).

160. Khaleel, A. et al. A Single Nucleotide Polymorphism (rs4236480) in TRPV5Calcium Channel Gene Is Associated with Stone Multiplicity in Calcium Nephrolithiasis Patients. Mediat Inflamm 2015, 1-7 (2015).

161. Lu, X. et al. Urolithiasis/Endourology In Silico Screening and Molecular Dynamic Study of Nonsynonymous Single Nucleotide Polymorphisms Associated with Kidney Stones in the SLC26A6 Gene. J Urology 196, 118-123 (2016).

162. Suzuki, Y. et al. Gain-of-function haplotype in the epithelial calcium channel TRPV6 is a risk factor for renal calcium stone formation. Hum Mol Genet 17, 1613-1618 (2008).

163. Jiang, Z. et al. Calcium oxalate urolithiasis in mice lacking anion transporter Slc26a6. Nat Genet 38, 474-478 (2006).

164. Jiang, H. et al. High expression of SLC26A6 in the kidney may contribute to renal calcification via an SLC26A6-dependent mechanism. Peerj 6, e5192-17 (2018).

165. Liu, C.-C. et al. Association of vitamin D receptor (Fok-I) polymorphism with the clinical presentation of calcium urolithiasis. Bju Int 99, 1534-1538 (2007).

166. Chen, W. C., Chen, H. Y., Hsu, C. D., Wu, J. Y. \& Tsai, F. J. No association of vitamin D receptor gene BsmI polymorphisms with calcium oxalate stone formation. Mol Urol 5, 7-10 (2001).

167. Gunes, S. et al. Vitamin D receptor gene polymorphisms in patients with urolithiasis. Urol Res 34, 47-52 (2006).

168. Moyano, M. J. et al. Alterations in bone mineral metabolism in patients with calcium kidney stone disease and polymorphism of vitamin D receptor. Preliminary results. Nefrologia: publicacion oficial de la Sociedad Espanola Nefrologia 27, 694-703 (2007).

169. Bid, H. K., Chaudhary, H. \& Mittal, R. D. Association of vitamin-D and calcitonin receptor gene polymorphism in paediatric nephrolithiasis. Pediatr Nephrol 20, 773-776 (2005).

170. Jackman, S. V. et al. Familial calcium stone disease: TaqI polymorphism and the vitamin D receptor. J Endourol 13, 313-316 (1999).

171. Ruggiero, M., Pacini, S., Amato, M., Aterini, S. \& Chiarugi, V. Association between Vitamin D Receptor Gene Polymorphism and Nephrolithiasis. Miner Electrol Metab 25, 185 190 (1999).

172. Liu, W. et al. Vitamin D receptor gene (VDR) polymorphisms and the urolithiasis risk: an updated meta-analysis based on 20 case-control studies. Urolithiasis 42, 45-52 (2013).

173. Zhang, P., Nie, W. \& Jiang, H. Effects of vitamin D receptor polymorphisms on urolithiasis risk: a meta-analysis. Bmc Med Genet 14, 104 (2013).

174. Lin, H. et al. HIPK2 polymorphisms rs2058265, rs6464214, and rs 7456421 were associated with kidney stone disease in Chinese males not females. Gene 653, 51-56 (2018). 
175. Liu, C.-C. et al. The impact of osteopontin promoter polymorphisms on the risk of calcium urolithiasis. Clin Chim Acta 411, 739-743 (2010).

176. Safarinejad, M. R., Shafiei, N. \& Safarinejad, S. Association between polymorphisms in osteopontin gene (SPP1) and first episode calcium oxalate urolithiasis. Urolithiasis 41, 303-313 (2013).

177. Gao, B. et al. A Polymorphism of Matrix Gla Protein Gene is Associated With Kidney Stones. J Urology 177, 2361-2365 (2007).

178. Lu, X. et al. A polymorphism of matrix Gla protein gene is associated with kidney stone in the Chinese Han population. Gene 511, 127-130 (2012).

179. Goiko, M. et al. Peptides of Matrix Gla Protein Inhibit Nucleation and Growth of Hydroxyapatite and Calcium Oxalate Monohydrate Crystals. Plos One 8, e80344-11 (2013).

180. LI, D. et al. Meta-analysis of the urokinase gene 3'-UTR T/C polymorphism and susceptibility to urolithiasis. Biomed Reports 1, 369-374 (2013).

181. Langman, C. B. A rational approach to the use of sophisticated genetic analyses of pediatric stone disease. Kidney Int 93, 15-18 (2018).

\section{Acknowledgements}

The authors are supported by: National Institute for Health Research (NIHR) Academic Clinical Lectureship (S.H.); Kidney Research UK project grant (RP_030_20180306; S.H.); Wellcome Trust Investigator Award (R.V.T.); NIHR Oxford Biomedical Research Centre Programme (RVT); and NIHR Senior Investigator Award (R.V.T.).

\section{Author contributions}

The authors contributed equally to all aspects of the article.

\section{Competing interests}

The authors declare no competing interests.

Publisher's note

Springer Nature remains neutral with regard to jurisdictional claims in published maps and institutional affiliations. 
ExAC database: http://exac.broadinstitute.org/

\section{Key points}

- Studies suggest that the prevalence of monogenic kidney stone disease in patients attending kidney stone clinics is $\sim 15 \%$.

- For patients without a monogenic cause of nephrolithiasis, the heritability of kidney stone disease and hypercalciuria is $>45 \%$ and $>50 \%$, respectively.

- Increased understanding of the genetic factors contributing to kidney stone disease helps to improve our understanding of the pathogenesis of this condition.

- Identification of a monogenic cause of kidney stone disease facilitates optimal stone prevention management and identification of associated phenotypes.

- Advances in our understanding of the polygenic factors contributing to risk of kidney stone disease might enable a precision medicine approach.

Table 1 | Monogenetic causes of kidney stones classified by urinary phenotype.

\begin{tabular}{|c|c|c|c|c|}
\hline Disorder & Genes & Inheritance & Phenotype & Management \\
\hline \multicolumn{5}{|l|}{ Hypercalciuria } \\
\hline $\begin{array}{l}\text { Familial } \\
\text { hypercalciuria }\end{array}$ & $\begin{array}{l}A D C Y 10, \\
V D R\end{array}$ & $\mathrm{AD}$ & Normocalcaemia & Thiazide \\
\hline $\begin{array}{l}\text { Autosomal dominant } \\
\text { hypocalcaemia }\end{array}$ & $\begin{array}{l}\text { CASR, } \\
\text { GNA11 }\end{array}$ & $\mathrm{AD}$ & $\begin{array}{l}\text { Hypocalcaemia, } \\
\text { hyperphosphataemia, } \\
\text { inappropriately low PTH. }\end{array}$ & $\begin{array}{l}\text { Use caution with vitamin D and } \\
\text { hypocalcaemia correction as they } \\
\text { might cause hypercalciuria }\end{array}$ \\
\hline Bartter syndrome & $\begin{array}{l}\text { NKCC2 } \\
(S L C 12 A 1), \\
\text { ROMK } \\
(K C N J 1), \\
C L C N K B, \\
B S N D, \\
C A S R, \\
C L C N 5\end{array}$ & $\begin{array}{l}\mathrm{AD}, \mathrm{AR} \text { or } \\
\mathrm{XLR}\end{array}$ & Hypokalaemia, alkalosis & $\begin{array}{l}\text { Indometacin, aldosterone } \\
\text { antagonist, electrolytes as required }\end{array}$ \\
\hline
\end{tabular}




\begin{tabular}{|c|c|c|c|c|}
\hline Dent's disease & $\begin{array}{l}\text { CLCN5, } \\
O C R L\end{array}$ & XLR & $\begin{array}{l}\text { LMW proteinuria and renal } \\
\text { impairment in men; solitary } \\
\text { hypercalciuria in female } \\
\text { carriers. }\end{array}$ & $\begin{array}{l}\text { Screen for osteomalacia and } \\
\text { opthalmology phenotypes if } O C R L \\
\text { mutation; use thiazides with } \\
\text { caution }\end{array}$ \\
\hline $\begin{array}{l}\text { Hypophosphataemic } \\
\text { rickets }\end{array}$ & $\begin{array}{l}\text { SLC34A1, } \\
\text { SLC34A3, } \\
\text { SLC9A3R1 }\end{array}$ & AR & $\begin{array}{l}\text { Low serum phosphate, } \\
\text { increased phosphate } \\
\text { excretion, elevated } 1,25 \\
\text { vitamin D }\end{array}$ & $\begin{array}{l}\text { Screen for osteomalacia; phosphate } \\
\text { replacement without vitamin D }\end{array}$ \\
\hline $\begin{array}{l}\text { Familial } \\
\text { hypomagnesaemia } \\
\text { with hypercalciuria } \\
\text { and nephrocalcinosis }\end{array}$ & $\begin{array}{l}\text { CLDN16, } \\
\text { CLDN19 }\end{array}$ & $\mathrm{AR}$ & $\begin{array}{l}\text { Low serum calcium and } \\
\text { magnesium, raised urinary } \\
\text { magnesium; } C L D N 19 \\
\text { mutations associated with } \\
\text { macular colobomata, } \\
\text { myopia and nystagmus } \\
\end{array}$ & $\begin{array}{l}\text { Magnesium replacement; use } \\
\text { caution with vitamin D } \\
\text { replacement; assess for } \\
\text { opthalmological phenotypes with } \\
\text { CLDN19 mutations }\end{array}$ \\
\hline $\begin{array}{l}\text { Infantile } \\
\text { hypercalcaemia }\end{array}$ & $\begin{array}{l}\text { CYP24A1, } \\
\text { SLC } 34 A 1\end{array}$ & $\mathrm{AR}$ & Hypercalcaemia & $\begin{array}{l}\text { CYP24A1: inhibitor of vitamin D } \\
\text { synthesis (e.g. fluconazole) } \\
\text { SLC34A1: phosphate replacement }\end{array}$ \\
\hline \multicolumn{5}{|l|}{ Cystinuria } \\
\hline- & $\begin{array}{l}\text { SLC } 3 A 1 \\
\text { SLC7A9 }\end{array}$ & $\begin{array}{l}\text { AR or AD } \\
\text { with } \\
\text { incomplete } \\
\text { penetrance }\end{array}$ & Solitary cystinuria & $\begin{array}{l}\text { Urinary alkalinization; thiol- } \\
\text { binding drugs such as D- } \\
\text { penacillamine, alpha- } \\
\text { mercaptopropionylglycine and } \\
\text { captopril; aggressive urinary } \\
\text { dilution }\end{array}$ \\
\hline \multicolumn{5}{|l|}{ Hyperuricosuria } \\
\hline $\begin{array}{l}\text { Defective purine } \\
\text { metabolism }\end{array}$ & $\begin{array}{l}\text { HRPT1, } \\
\text { PRPS1 }\end{array}$ & XLR & $\begin{array}{l}\text { Hyperuricaemia, } \\
\text { learning,disability, renal } \\
\text { failure, hearing loss } \\
(P R P S 1)\end{array}$ & $\begin{array}{l}\text { Urinary alkalinization; allopurinol } \\
\text { or febuxostat; hearing screening; } \\
\text { monitor renal function; }\end{array}$ \\
\hline $\begin{array}{l}\text { Renal uric acid } \\
\text { wasting }\end{array}$ & $\begin{array}{l}\text { SLC22A12, } \\
\text { SLC2A9 }\end{array}$ & $\mathrm{AD}$ or $\mathrm{AR}$ & Hypouricosuria & $\begin{array}{l}\text { Urinary alkalinization; allopurinol } \\
\text { or febuxostat }\end{array}$ \\
\hline \multicolumn{5}{|l|}{ Xanthinuria } \\
\hline- & $\begin{array}{l}\text { XDH, } \\
\text { MOCOS, } \\
\text { MOCS1, } \\
\text { MOCS2, } \\
\text { GPHN }\end{array}$ & AR & $\begin{array}{l}\text { Hypouricosuria. } \\
M O C S 1, M O C S 2, G P H N \\
\text { mutations result in } \\
\text { increased serum sulphite } \\
\text { levels that can cause } \\
\text { seizures, hypotonia. } \\
\end{array}$ & $\begin{array}{l}\text { Low purine diet; neurological } \\
\text { screening for } M O C S 1, M O C S 2 \text { and } \\
G P H N \text { mutations }\end{array}$ \\
\hline \multicolumn{5}{|c|}{ Failed urinary acidification } \\
\hline- & $\begin{array}{l}\text { SLC4A1, } \\
\text { ATP6VB1, } \\
\text { ATP6VA4, } \\
\text { CA2 }\end{array}$ & $\mathrm{AD}$ or $\mathrm{AR}$ & $\begin{array}{l}\text { Hypokalaemia, } \\
\text { hyperchloraemia, } \\
\text { hypercalciuria, } \\
\text { hyperphosphaturia, } \\
\text { hypocitraturia. hearing loss } \\
\text { with } A T P 6 V B 1 \text { and } \\
\text { ATP6VA4 mutations }\end{array}$ & $\begin{array}{l}\text { Alkalinization with sodium } \\
\text { bicarbonate or alkaline citrate; } \\
\text { hearing screening; assessment for } \\
\text { osteomalacia }\end{array}$ \\
\hline \multicolumn{5}{|l|}{ Hyperoxaluria } \\
\hline- & $\begin{array}{l}\text { AGXT, } \\
\text { GRHPR, } \\
\text { HOGA1, } \\
\text { SLC26A1 }\end{array}$ & $\mathrm{AR}$ & $\begin{array}{l}\text { Renal impairment, } \\
\text { hyperoxalaemia and } \\
\text { systemic oxalate deposition; } \\
\text { orthopaedic, cardiac and } \\
\text { opththalmological } \\
\text { phenotypes }\end{array}$ & $\begin{array}{l}\text { Pyridoxine for } A G X T \text { mutations; } \\
\text { assess for systemic oxalate } \\
\text { deposition; no requirement for } \\
\text { strict oral oxalate. In contrast, oral } \\
\text { oxalate restriction is beneficial in } \\
\text { enteric hyperoxaluria; increase } \\
\text { urinary inhibitors of calcium } \\
\text { oxalate crystallization with } \\
\text { potassium citrate, magnesium oxide } \\
\text { and orthophosphate; aggressive } \\
\text { urine dilution }\end{array}$ \\
\hline \multicolumn{5}{|c|}{ Dihydroxyadenine crystals } \\
\hline- & $A P R T$ & AR & $\begin{array}{l}\text { Radiolucent stones and } \\
\text { renal impairment }\end{array}$ & Allopurinol or febuxostat \\
\hline
\end{tabular}

AD; autosomal dominant; AR, autosomal recessive; LMW, low molecular weight; XLR, X-linked

recessive. 
Figure 1 | Radiographic appearance of kidney stone disease in three patients. Upper panel images are plain abdominal radiographs and lower panel images are non-contrast CT sagittal sections. Stones are marked with squares and/or circles in the upper panels and with arrows in the lower panels. R, right; L, left. a | Calcium oxalate stone in the left kidney appearing radiopaque on plain abdominal radiograph. $\mathbf{b}$ | Cystine stone in the left kidney that demonstrates reduced radiopacity and is faintly visible on plain abdominal radiograph. $\mathbf{c}$ | Uric acid stone in right ureter is radiolucent and not visible on plain abdominal radiograph.

Figure 2: Monogenetic disorders of nephrolithiasis resulting in renal tubular dysfunction. a In the proximal convoluted tubule, low molecular weight (LMW) proteins (black circles) are endocytosed by megalin and cubulin (red apical receptor). Endosomal acidification occurs via hydrogen ion transport via chloride channel protein 5 (ClC-5) (also known as $\mathrm{H}^{+} / \mathrm{Cl}^{-}$exchange transporter 5 and encoded by CLCN5) and V-ATPase and enables ligand-receptor dissociation and receptor recycling. CLCN5 mutations are found in Dent disease. Phosphate uptake in the proximal tubule takes place via NPT2a and NPT2c transporters; mutations in genes encoding these proteins are found in hereditary hypophosphatemic rickets with hypercalciuria. Dibasic amino acids are reabsorbed from the tubular lumen via the $\mathrm{b}^{\mathrm{o},+}$ amino acid transport system, a heterodimer comprised of rBAT and $\mathrm{b}^{\mathrm{O},+} \mathrm{AT}$ subunits. Mutations in $\mathrm{rBAT}$ and $\mathrm{b}^{\mathrm{O},+} \mathrm{AT}$ are found in patients with cystinuria. Uric acid enters the proximal tubular cells via solute carrier family 22 member 12 (also known as urate anion exchanger 1 (URAT1)) and exits the basolateral membrane via solute carrier family 2, facilitated glucose transporter member 9 (GLUT9). Mutations in genes encoding URAT1 and GLUT9 are found in hereditary hyperuricosuria. $\mathbf{b} \mid$ In the thick ascending limb of the loop of Henle, sodium-potassiumchloride cotransporter 2 (NKCC2, also known as SLC12A1) and renal outer-medullary potassium channel (ROMK; also known as KCNJ1) establish a lumen-positive trans-tubular potential difference that drives calcium $\left(\mathrm{Ca}^{2+}\right)$ reabsorption. The calcium-sensing receptor (CaSR) acts to inhibit NKCC2. Sodium ions $\left(\mathrm{Na}^{+}\right)$are transported across the basolateral membrane via $\mathrm{Na}^{+}-\mathrm{K}^{+}$ATPase and $\mathrm{Cl}^{-}$via the voltage-gated chloride channel CLC-Kb, which acts with Barttin. Mutations in genes encoding NKCC2, 
ROMK, CLC-Kb, Barttin and the CaSR result in Bartter syndrome. Claudins maintain tight junctions in the thick ascending limb of the loop of Henle and regulate the degree to which the junctions are permeable to cations. Mutations in CLDN16 and CLDN19 result in familial hypercalciuric hypomagnesaemia with nephrocalcinosis. $\mathbf{c} \mid$ In the collecting duct, carbonic anhydrase 2 (CA2) catalyses the conversion of water and carbon dioxide into hydrogen ions and bicarbonate within $\alpha$-intercalated cells. Hydrogen ions are secreted into the lumen via the $\mathrm{H}^{+}$-ATPase and $\mathrm{H}^{+} / \mathrm{K}^{+}$-ATPase pumps and bicarbonate exits the basolateral membrane via chloride-bicarbonate exchanger, AE1 (also known as band 3 anion transport protein). Mutations in genes encoding $\mathrm{H}^{+}$-ATPase, AE1 and CA2 result in impaired urinary acidification and distal renal tubular acidosis.

Figure 3 | Vitamin D metabolism. 7-dehydrocholesterol is converted to cholecalciferol (vitamin D) in the skin under the influence of ultraviolet light and heat. Cholecalciferol is also available through dietary intake. Cholecalciferol undergoes 25-hydroxylation in the liver by vitamin D 25-hydroxylase (encoded by $C Y P 2 R 1)$, converting it to 25 -hydroxyvitamin $\mathrm{D}\left(25-(\mathrm{OH}) \mathrm{D}_{3}\right)$. The final step in the activation of vitamin $\mathrm{D}$ takes place in the kidney where 25-hydroxyvitamin D 1 $\alpha$-hydroxylase (encoded by CYP27B1) hydroxylates $25-(\mathrm{OH}) \mathrm{D}_{3}$ at the $1 \alpha$ position to form 1,25-dihydroxyvitamin $\mathrm{D}\left(1,25-(\mathrm{OH})_{2} \mathrm{D}_{3}\right)$, also called calcitriol. Active vitamin $\mathrm{D}\left(1,25-(\mathrm{OH})_{2} \mathrm{D}_{3}\right)$ is inactivated by 1 ,25-dihydroxyvitamin $\mathrm{D}_{3}$ 24-hydroxylase (encoded by CYP24A1) which generates a 24-hydroxylated form 1,24,25-trihydroxyvitamin D (1,24,25$\left.(\mathrm{OH})_{2} \mathrm{D}_{3}\right)$. CYP24A1 also hydroxylates $25-(\mathrm{OH}) \mathrm{D}$ to form 24,25-dihydroxyvitamin $\mathrm{D}\left(24,25-(\mathrm{OH} 2) \mathrm{D}_{3}\right)$.

Figure 4 | Schematic representation of purine metabolism. Purine nucleotides are synthesized via the phosphorylation of ribose-5-phosphate by phosphoribosyl pyrophosphate synthase (PRPPS; also known as ribose-phosphate pyrophosphokinase 1) to form phosphoribosyl pyrophosphate (PRPP). Hypoxanthine guanine phosphoribosyltransferase (HGPRT, encoded by HPRTI) and adenine phosphoribosyltransferase (APRT) form part of the salvage pathway, converting free bases (adenine, hypoxanthine and guanine) back to nucleoside-5'-monophosphates adenosine monophosphate (AMP), inosine monophosphate (IMP) and guanosine monophosphate (GMP). Xanthine dehydrogenase (XDH) catalyses the formation of uric acid from hypoxanthine and 2,8-dihydroxyadenine from adenine. Molecular defects in the enzymes PRPPS, HGPRT, XDH and APRT (shown in red) can result in hyperuricosuria or increased 2,8-dihydroxyadenine excretion. 
Box 1 | Investigations and dietary stone prevention strategies for kidney stone formers

\section{Investigations}

Blood tests: calcium, chloride, creatinine, bicarbonate, potassium, phosphate, uric acid, PTH in cases where serum calcium is high normal or high.

24 hour urine collection: calcium excretion, oxalate excretion, uric acid excretion, citrate excretion, sodium excretion, magnesium excretion, phosphate excretion, cystine excretion, urinary volume, urinary $\mathrm{pH}$

Stone analysis

\section{Dietary stone prevention strategies}

Increase: fluid intake, dietary fresh fruit, dietary fibre

Reduce: dietary animal protein, dietary sodium, dietary oxalate

\section{Box 2: Candidate genes from kidney stone genome-wide association studies}

$A B C G 2$ : ATP binding cassette subfamily $\mathrm{G}$ member 2

ALPL: Alkaline phosphatase, biomineralization associated

$A Q P 1:$ Aquaporin 1

BCAS3: BCAS3 microtubule associated cell migration factor

$B C R$ : BCR activator of RhoGEF and GTPase

CASR: calcium-sensing receptor

CLDN14: claudin 14

CYP24A1: cytochrome P450 family 24 subfamily A member 1

$D G K D$ : diacylglycerol kinase delta

$D G K H$ : diacylglycerol kinase eta

EPB41L2: erythrocyte membrane protein band 4.1 like 2

FTO: FTO alpha-ketoglutarate dependent dioxygenase

GIPC1: GIPC PDZ domain containing family member 1

GCKR: glucokinase regulator

HIBADH: 3-hydroxyisobutyrate dehydrogenase

KCNK5: Potassium two pore domain channel subfamily 5 member 5

POU2AF1: POU class 2 homeobox associating factor 1

SLC22A2: solute carrier family 22 member 2 
SLC34A1: solute carrier family 34 member 1

SCNNIB: sodium channel epithelial 1 beta subunit

SOX9: SRY-box transcription factor 9

TFAP2B: transcription factor AP-2 beta

TRPV5: transient receptor potential cation channel subfamily V member 5

WDR72: WD repeat domain 72

UMOD: uromodulin 
Supplementary Table 1 | Monogenetic causes of kidney stone disease

\begin{tabular}{|c|c|c|c|c|c|c|}
\hline Disease & Inheritance & Gene & $\begin{array}{c}\text { Chromosomal } \\
\text { location }\end{array}$ & Gene product & $\begin{array}{c}\text { OMIM } \\
\text { number }\end{array}$ & $\begin{array}{r}\text { Stone X-ray } \\
\text { appearance }\end{array}$ \\
\hline \multirow[t]{3}{*}{ Idiopathic hypercalciuria } & $\mathrm{AD}$ & $A D C Y 10$ & $1 \mathrm{q} 24.2$ & Adenylyl cyclase & 143870 & \multirow{3}{*}{ Radiopaque } \\
\hline & AD & $V D R$ & $12 \mathrm{q} 13.11$ & Nuclear hormone receptor for vitamin D3 & - & \\
\hline & $\mathbf{A D}$ & $?$ & $9 \mathrm{p} 33.2-\mathrm{q} 34.2$ & $?$ & - & \\
\hline \multicolumn{6}{|l|}{ Autosomal dominant hypocalcaemia } & \multirow{3}{*}{ Radiopaque } \\
\hline Type 1 & $\mathrm{AD}$ & CASR & $3 \mathrm{p} 21.1$ & Calcium-sensing receptor & 601199 & \\
\hline Type 2 & $\mathrm{AD}$ & GNA11 & $19 \mathrm{q} 13.3$ & G-protein subunit $\alpha 11$ & 615361 & \\
\hline \multicolumn{6}{|l|}{ Bartter syndrome } & \multirow{6}{*}{ Radiopaque } \\
\hline Type I & $\mathrm{AR}$ & $\begin{array}{l}N K C C 2 \\
(S L C 12 A 1) \\
\end{array}$ & $15 q 21.1$ & Sodium-potassium-chloride cotransporter & 601678 & \\
\hline Type II & AR & $\begin{array}{l}\text { ROMK } \\
(K C N J 1)\end{array}$ & $11 \mathrm{q} 24.3$ & ATP-sensitive potassium channel & 241200 & \\
\hline Type III & $\mathrm{AR}$ & $C L C N K B$ & $1 \mathrm{p} 36.13$ & Voltage-gated chloride channel CLCNKB & 607364 & \\
\hline Type IV & $\mathrm{AR}$ & $B S N D$ & $1 \mathrm{p} 32.3$ & $\begin{array}{l}\text { Barttin encoded by BSND is an essential } \\
\text { subunit for the CLCNKB chloride channel }\end{array}$ & 602522 & \\
\hline Type V & $\mathrm{AD}$ & CASR & $3 \mathrm{p} 21.1$ & Calcium-sensing receptor & 601198 & \\
\hline Type VI & XLR & CLCN5 & $\mathrm{Xp} 11.23$ & Voltage-gated chloride channel & - & \\
\hline \multicolumn{6}{|l|}{ Dent disease } & \multirow{3}{*}{ Radiopaque } \\
\hline Type 1 & XLR & CLCN5 & $\mathrm{Xp} 11.23$ & Voltage-gated chloride channel & 300009 & \\
\hline Type 2 & XLR & OCRL & $\mathrm{Xp} 26.1$ & Inositol polyphosphate 5-phosphatase & 300555 & \\
\hline $\begin{array}{l}\text { Hereditary hypophosphataemic rickets } \\
\text { with hypercalciuria }\end{array}$ & $\mathrm{AR}$ & SLC34A3 & $9 \mathrm{q} 34.3$ & $\begin{array}{l}\text { Sodium-dependent phosphate transporter } \\
\text { 2c }\end{array}$ & 241530 & Radiopaque \\
\hline & & & & & & \\
\hline \multicolumn{6}{|l|}{ Hypophosphataemia and nephrolithiasis } & \multirow{3}{*}{ Radiopaque } \\
\hline Type 1 & $\mathrm{AD}$ & SLC34A1 & $5 q 35.3$ & $\begin{array}{l}\text { Sodium-dependent phosphate transporter } \\
\text { 2a }\end{array}$ & 612286 & \\
\hline Type 2 & $\mathrm{AD}$ & SLC9A3R1 & $17 \mathrm{q} 25.1$ & $\begin{array}{l}\text { Sodium/hydrogen exchange regulatory } \\
\text { Factor } 1\end{array}$ & 612287 & \\
\hline
\end{tabular}




\begin{tabular}{|c|c|c|c|c|c|c|}
\hline $\begin{array}{l}\text { Familial hypomagnesaemia with } \\
\text { hypercalciuria and nephrocalcinosis }\end{array}$ & AR & CLDN16 & $3 q 28$ & Claudin-16 & 248250 & Radiopaque \\
\hline $\begin{array}{l}\text { Familial hypomagnesaemia with } \\
\text { hypercaclciuria and nephrocalcinosis } \\
\text { with severe ocular involvement }\end{array}$ & AR & CLDN19 & $1 \mathrm{q} 34.2$ & Claudin-19 & 248190 & Radiopaque \\
\hline $\begin{array}{l}\text { Autosomal dominant distal renal tubular } \\
\text { acidosis }\end{array}$ & $\mathrm{AD}$ & SLC4A1 & $17 q 21.31$ & Chloride/bicarbonate exchanger, AE1 & 1479800 & Radiopaque \\
\hline $\begin{array}{l}\text { Autosomal recessive distal renal tubular } \\
\text { acidosis with progressive nerve deafness }\end{array}$ & AR & ATP6V1B1 & $2 \mathrm{p} 13.3$ & $\begin{array}{l}\text { B1 subunit of } \alpha \text {-intercalated cell } \mathrm{H}^{+}- \\
\text {ATPase }\end{array}$ & 267300 & Radiopaque \\
\hline $\begin{array}{l}\text { Autosomal recessive distal renal tubular } \\
\text { acidosis }\end{array}$ & AR & ATP6V0A4 & $7 q 34$ & $\begin{array}{l}\text { A4 subunit of } \alpha \text {-intercalated cell } \mathrm{H}^{+}- \\
\text {ATPase }\end{array}$ & 602722 & Radiopaque \\
\hline $\begin{array}{l}\text { Autosomal recessive distal renal tubular } \\
\text { acidosis }\end{array}$ & AR & CA2 & & Carbonic anhydrase 2 & & Radiopaque \\
\hline $\begin{array}{l}\text { Autosomal recessive distal renal tubular } \\
\text { acidosis }\end{array}$ & AR & WDR72 & & WD repeat-containing protein 72 & & Radiopaque \\
\hline $\begin{array}{l}\text { Autosomal recessive distal renal tubular } \\
\text { acidosis }\end{array}$ & AR & FOXII & & Forkhead box protein I1 & & Radiopaque \\
\hline \multicolumn{6}{|l|}{ Infantile hypercalcaemia } & \multirow{3}{*}{ Radiopaque } \\
\hline Type 1 & $\mathrm{AR}$ & CYP24A1 & $20 \mathrm{q} 13.2$ & 24-hydroxylase enzyme & 143880 & \\
\hline Type 2 & AR & SLC34A1 & $5 q 35.3$ & $\begin{array}{l}\text { Sodium-dependent phosphate transporter } \\
2 \mathrm{a}\end{array}$ & 616963 & \\
\hline \multicolumn{6}{|l|}{ Primary hyperoxaluria } & \multirow[b]{2}{*}{ Radiopaque } \\
\hline Type 1 & $\mathrm{AR}$ & $A G X T$ & $2 q 37.3$ & $\begin{array}{l}\text { Peroxisomal alanine-glyoxylate amino- } \\
\text { transferase }\end{array}$ & 259900 & \\
\hline
\end{tabular}




\begin{tabular}{|c|c|c|c|c|c|c|}
\hline Type 2 & $\mathrm{AR}$ & GRHPR & $9 \mathrm{q} 13.2$ & $\begin{array}{l}\text { Glyoxylate reductase/hydroxypyruvate } \\
\text { reductase }\end{array}$ & 260000 & \\
\hline Type 3 & AR & HOGAI & $10 \mathrm{q} 24.2$ & 4-hydroxy-2-oxoglutarate aldolase & 613616 & \\
\hline Calcium oxalate nephrolithiasis & AR & SLC26A1 & $4 \mathrm{p} 16.3$ & Basolateral sulfate/oxalate exchanger & 167030 & \\
\hline \multicolumn{6}{|l|}{ Cystinuria } & \multirow{3}{*}{$\begin{array}{l}\text { Poor } \\
\text { radiopacity }\end{array}$} \\
\hline Type A & AR & SLC3A1 & $2 \mathrm{p} 21$ & $\begin{array}{l}\text { rBAT (part of } b^{o,+} \text { amino acid transport } \\
\text { system) }\end{array}$ & 220100 & \\
\hline Type B & $\mathrm{AD}$ & SLC7A9 & $19 q 31.11$ & $\begin{array}{l}\mathrm{b}^{\mathrm{o},+} \mathrm{AT} \text { (part of } \mathrm{b}^{\mathrm{o},+} \text { amino acid transport } \\
\text { system) }\end{array}$ & 220100 & \\
\hline & & & & & & \\
\hline $\begin{array}{l}\text { Lesch-Nyhan or Kelley-Seegmiller } \\
\text { syndrome }\end{array}$ & XLR & HPRT1 & Xq26.2-q26.3 & $\begin{array}{l}\text { Hypoxanthine guanine } \\
\text { phosphoribosyltransferase }\end{array}$ & 300322 & Radiolucent \\
\hline PRPPS superactivity & XLR & PRPS1 & $\mathrm{Xq} 22.3$ & Phosphoribosyl pyrophosphate synthase & 311850 & Radiolucent \\
\hline & & & & & & \\
\hline \multicolumn{6}{|l|}{ Renal hypouricaemia } & \multirow{3}{*}{ Radiolucent } \\
\hline Type 1 & AR & SLC22A12 & $11 \mathrm{q} 13.1$ & $\begin{array}{l}\text { URAT1 (proximal renal tubular uric acid } \\
\text { transporter) }\end{array}$ & 607096 & \\
\hline Type 2 & $\mathrm{AD} / \mathrm{AR}$ & SLC2A9 & $4 \mathrm{p} 16.1$ & $\begin{array}{l}\text { GLUT9 (proximal renal tubular uric acid } \\
\text { transporter) }\end{array}$ & 606142 & \\
\hline \multicolumn{6}{|l|}{ Hereditary xanthinuria } & \multirow{3}{*}{ Radiolucent } \\
\hline Type 1 & $\mathrm{AR}$ & $\mathrm{XDH}$ & $2 \mathrm{p} 23.1$ & Xanthine dehydrogenase & 607633 & \\
\hline Type 2 & AR & MOCOS & $18 \mathrm{q} 12.2$ & Molybdenum cofactor sulfurase & 603592 & \\
\hline \multicolumn{6}{|l|}{ Molybdenem cofactor deficiency } & \multirow{4}{*}{ Radiolucent } \\
\hline Type A & AR & MOCS1 & $6 \mathrm{p} 21.2$ & $\begin{array}{l}\text { Molybdenum cofactor biosynthesis protein } \\
1\end{array}$ & 603707 & \\
\hline Type B & $\mathrm{AR}$ & MOCS2 & $5 q 11.2$ & $\begin{array}{l}\text { Molybdenum synthase sulfur carrier } \\
\text { subunit }\end{array}$ & 603708 & \\
\hline Type C & AR & GPHN & $14 q 23.3-q 24.1$ & $\begin{array}{l}\text { Gephyrin (catalyst for molybdenum } \\
\text { cofactor biosynthesis) }\end{array}$ & 603930 & \\
\hline
\end{tabular}


Adenine phosphoribosyltransferase

AR

\begin{tabular}{l|l} 
APRT & $16 \mathrm{q} 24.3$
\end{tabular}

Adenine phosphoribosyltransferase

614723

Radiolucent

deficiency

AD, Autosomal dominant; AR, Autosomal recessive; XLR, X-linked recessive. Disorders of calcium nephrolithiasis. Disorders of non-calcium nephrolithiasis. 